\title{
Postnatal Development of the Amygdala: A Stereological Study in Macaque Monkeys
}

\author{
Loïc J. Chareyron, ${ }^{1}$ Pamela Banta Lavenex, ${ }^{1}$ David G. Amaral, ${ }^{2}$ and Pierre Lavenex ${ }^{1 *}$ \\ ${ }^{1}$ Laboratory of Brain and Cognitive Development, Department of Medicine, University of Fribourg, Switzerland \\ ${ }^{2}$ Department of Psychiatry and Behavioral Sciences, Center for Neuroscience, California National Primate Research Center, \\ M.I.N.D. Institute, UC Davis, Davis, California, USA
}

\begin{abstract}
Abnormal development of the amygdala has been linked to several neurodevelopmental disorders, including schizophrenia and autism. However, the postnatal development of the amygdala is not easily explored at the cellular level in humans. Here we performed a stereological analysis of the macaque monkey amygdala in order to characterize the cellular changes underlying its normal structural development in primates. The lateral, basal, and accessory basal nuclei exhibited the same developmental pattern, with a large increase in volume between birth and 3 months of age, followed by slower growth continuing beyond 1 year of age. In contrast, the medial nucleus was near adult size at birth. At birth, the volume of the central nucleus was half of the adult value; this nucleus exhibited significant growth even after 1 year of age. Neither neuronal soma size,
\end{abstract}

nor neuron or astrocyte numbers changed during postnatal development. In contrast, oligodendrocyte numbers increased substantially, in parallel with an increase in amygdala volume, after 3 months of age. At birth, the paralaminar nucleus contained a large pool of immature neurons that gradually developed into mature neurons, leading to a late increase in the volume of this nucleus. Our findings revealed that distinct amygdala nuclei exhibit different developmental profiles and that the amygdala is not fully mature for some time postnatally. We identified different periods during which pathogenic factors might lead to the abnormal development of distinct amygdala circuits, which may contribute to different human neurodevelopmental disorders associated with alterations of amygdala structure and functions. J. Comp. Neurol. 520:1965-1984, 2012.

(C) 2011 Wiley Periodicals, Inc.

INDEXING TERMS: amygdaloid complex; emotion; fear; social behavior; neurons; astrocytes; oligodendrocytes; neuropil; neurodevelopmental disorders; anxiety; autism; schizophrenia

Abnormal structure or function of the amygdala has been implicated in the pathophysiology of a surprising number of psychiatric disorders, including anxiety (Kalin et al., 2004; Kim et al., 2011; Tye et al., 2011), depression (Drevets, 2003; Hamidi et al., 2004; Yang et al., 2010), bipolar disorder (Berretta et al., 2007; Kalmar et al., 2009; Usher et al., 2010), schizophrenia (Lawrie et al., 2003; Kreczmanski et al., 2007), and autism (Baron-Cohen et al., 2000; Schumann et al., 2004, 2009; Schumann and Amaral, 2006; Mosconi et al., 2009), as well as in neurological disorders such as epilepsy (Aliashkevich et al., 2003; Aroniadou-Anderjaska et al., 2008) and Alzheimer's disease (Vereecken et al., 1994; Ichinohe et al., 2009; Cavedo et al., 2011). To reconcile the diversity of disorders with which the amygdala is associated, one might speculate that there are sensitive developmental periods during which different environmental factors, hormonal influences, or other experiences could alter

(C) 2011 Wiley Periodicals, Inc. specific aspects of amygdala development, and thus contribute to the etiologies of such a variety of psychiatric disorders (Tottenham and Sheridan, 2009). It is important, therefore, to understand the normal time course and features of amygdala development. However, the poor availability of early postnatal brain tissue makes a study such as this impractical in the human. The use of the nonhuman primate, therefore, is a valuable proxy for

Grant sponsor: Swiss National Science Foundation; Grant numbers: PP00A-106701, PP00P3-124536; Grant sponsor: National Institutes of Health (NIH); Grant number: RO1-MH041479; conducted, in part, at the California National Primate Research Center (RR00169); Grant sponsor: Swiss National Science Foundation; Grant numbers: PMPDP3_122844, PMPDP3_128996 (to P.B.L.).

*CORRESPONDENCE TO: Dr. Pierre Lavenex, Laboratory of Brain and Cognitive Development, Department of Medicine, University of Fribourg, Chemin du Musée 5, CH-1700 Fribourg, Switzerland.

E-mail: pierre.lavenex@unifr.ch

Received September 22, 2011; Revised November 9, 2011; Accepted December 11, 2011

DOI 10.1002/cne.23023

Published online December 16, 2011 in Wiley Online Library (wileyonlinelibrary.com) 
establishing the cellular processes underlying primate amygdala development.

To date, however, there is no reliable description of the morphological characteristics, such as cell numbers and volumes of the main amygdala nuclei, during the first years of life in primates. Previous studies have described the prenatal development of the monkey amygdala (Kordower et al., 1992; Ulfig et al., 2003). Their findings are consistent with work carried out in the human (Humphrey, 1968), indicating that the basic architecture of the amygdala is well established at birth. In contrast, magnetic resonance imaging (MRI) studies of postnatal amygdala development performed in humans and nonhuman primates indicate a delayed maturation of this structure that potentially extends up to the end of the second decade in humans (Giedd et al., 1996; Schumann et al., 2004; Mosconi et al., 2009; Ostby et al., 2009; Payne et al., 2010). Of course, current MRI techniques do not have sufficient resolution to quantify the volumetric changes of distinct amygdala nuclei nor to characterize, at the cellular level, the underlying morphological changes.

The goal of the present study was to provide quantitative neuroanatomical information about the postnatal maturation of the primate amygdala. We implemented design-based stereological techniques to characterize the cellular development of the rhesus monkey (Macaca mulatta) amygdaloid complex from birth to 1 year of age and in young adulthood (5-9 years of age). We aimed to determine when the volumes and cell numbers of its six main nuclei (i.e., lateral, basal, accessory basal, paralaminar, central, and medial) reach an adult-like state. Understanding the normal time course of postnatal development of the primate amygdala, at the cellular level, will help to determine when specific structural and functional features develop in order to be able to predict how these maturational processes can be affected by factors that might underlie the development of pathology in humans.

\section{MATERIALS AND METHODS}

\section{Experimental animals}

Twenty-four rhesus monkeys, Macaca mulatta; four 1-day-olds (two males, two females), four 3-month-olds (two male, two females), four 6-month-olds (two males, two females), four 9-month-olds (two males, two females), four 1-year-olds (two males, two females), and four adults (5.3 and 9.4 years old, males; 7.7 and 9.3 years old females) were used for this study. Monkeys were born from multiparous mothers and raised at the California National Primate Research Center (CNPRC). They were maternally reared in $2,000 \mathrm{~m}^{2}$ outdoor enclosures and lived in large social groups until they were killed. These monkeys were the same animals used in quantitative studies of the monkey hippocampal formation (Jabès et al., 2010, 2011) and in a comparative study of the amygdala in young adult rats and monkeys (5-9year-old monkeys only; Chareyron et al., 2011). All experimental procedures were approved by the Institutional Animal Care and Use Committee of the University of California, Davis, and were conducted in accordance with the National Institutes of Health guidelines for the use of animals in research.

\section{Brain acquisition}

Monkeys were deeply anesthetized with an intravenous injection of sodium pentobarbital $(50 \mathrm{mg} / \mathrm{kg}$ intravenously; Fatal-Plus, Vortech Pharmaceuticals, Dearborn, $\mathrm{MI}$ ) and perfused transcardially with $1 \%$ and then $4 \%$ paraformaldehyde in $0.1 \mathrm{M}$ phosphate buffer (PB; pH 7.4) following protocols previously described (Lavenex et al., 2009). Coronal sections were cut using a freezing, sliding microtome (Microm HM 450, Microm International, Germany) in six series at $30 \mu \mathrm{m}$ and one series at $60 \mu \mathrm{m}$. The $60-\mu \mathrm{m}$ sections were collected in $10 \%$ formaldehyde solution in $0.1 \mathrm{M} \mathrm{PB}(\mathrm{pH} 7.4)$ and postfixed at $4^{\circ} \mathrm{C}$ for 4 weeks prior to Nissl staining with thionin. All other series were collected in tissue collection solution and kept at $-70^{\circ} \mathrm{C}$ until further processing (Lavenex et al., 2009).

\section{Histological processing}

The procedure for Nissl-stained sections followed our standard laboratory protocol described previously (Lavenex et al., 2009; Chareyron et al., 2011). Briefly, sections were taken from the $10 \%$ formaldehyde solution, thoroughly washed, mounted on gelatin-coated slides, and air-dried overnight at $37^{\circ} \mathrm{C}$. Sections were then defatted $2 \times 2$ hours in a mixture of chloroform/ethanol (1:1, vol), partially rehydrated and air-dried overnight at $37^{\circ} \mathrm{C}$. Sections were then fully rehydrated and stained 20 seconds in a $0.25 \%$ thionin solution (Fisher Scientific, Waltham, MA; cat. no. T-409), dehydrated, and coverslipped with DPX (BDH Laboratories, Poole, UK).

\section{Anatomical boundaries of the amygdala}

The nomenclature and the basic description of the morphological characteristics of the amygdala nuclei have been described in detail previously by Price et al. (1987), Amaral et al. (1992), and Pitkänen and Amaral (1998) for the cynomolgus monkey (Macaca fascicularis). We used these descriptions to determine the boundaries of the six main nuclei (i.e., lateral, basal, accessory basal, paralaminar, central, and medial) of the Macaca mulatta amygdala (Fig. 1) (Chareyron et al., 2011). 

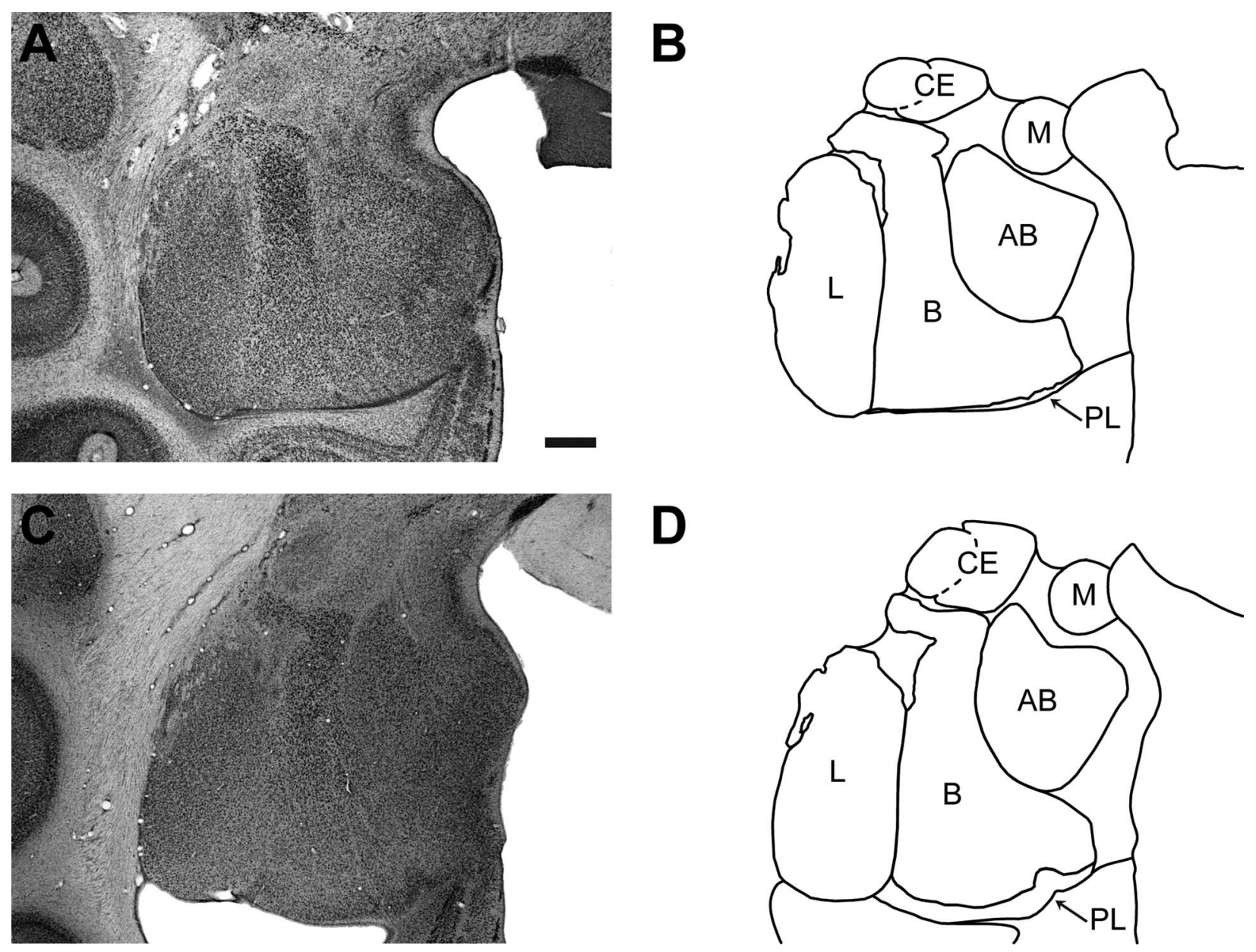

Figure 1. Low-magnification photomicrographs of a representative coronal section at a mid-rostrocaudal level of the rhesus monkey (Macaca mulatta) amygdala, which illustrate the locations of the six main amygdala nuclei in a newborn (A,B) and a 9-year-old (C,D) monkey. L: lateral; B: basal; PL: paralaminar; AB: accessory basal; CE: central; M: medial. Nonlabeled areas include the remaining nuclei of the amygdala (see Chareyron et al., 2011). Scale bar $=1 \mathrm{~mm}$ in A (applies to all).

\section{Stereological analyses}

Volume measurements, and neuron and glia counts were performed with Stereolnvestigator 9.0 (MicroBrightField, Williston, VT). We estimated the volume of the brain (telencephalon and diencephalon), the volume of the whole amygdala, and the volume of the main amygdala nuclei (lateral, basal, paralaminar, accessory basal, central, and medial) according to the Cavalieri principle on Nissl-stained sections cut at $60 \mu \mathrm{m}$ (Gundersen and Jensen, 1987; West and Gundersen, 1990; Lavenex et al., $2000 a, b)$. We used the section cutting thickness $(60 \mu \mathrm{m})$ to calculate the volume. Brain volume refers to the volume of the telencephalon and diencephalon bilaterally (ventricles were excluded). Twenty-nine to 37 sections per animal (1,920 $\mu \mathrm{m}$ apart), with the first section selected randomly within the first seven sections through the brain, were used for brain volume measurements. An average of 14 sections per animal (480 $\mu \mathrm{m}$ apart), with the first section selected randomly within the first two sections through the amygdala, was used to measure the volume of the whole amygdala (for a complete list of amygdala nuclei, see Chareyron et al., 2011). We compared total amygdala volumes in the left and the right hemisphere and did not find evidence of lateralization $\left(\mathrm{F}_{1,23}=0.0977, P=0.757\right)$. We therefore performed estimates unilaterally for the other parameters (see below). About 28 sections per animal (240 $\mu \mathrm{m}$ apart) were used for volume estimates of the main amygdala nuclei. At the rostral pole of the amygdala the paralaminar nucleus extends rostrally and dorsally to the lateral and basal nuclei. As a consequence, the first coronal section may be oriented tangentially to the paralaminar nucleus, resulting in an overrepresentation of this region in some cases. We therefore excluded this rostral, dorsal portion of the paralaminar nucleus, and restricted our analysis to the main part of the nucleus located ventral to 


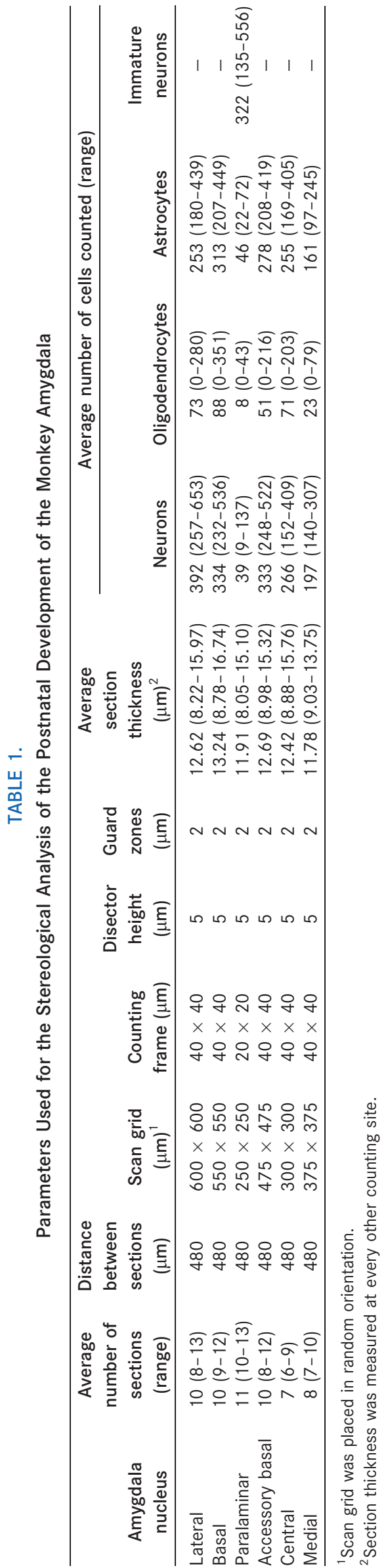

the basal nucleus. Since there was no lateralization for overall amygdala size, we estimated the volumes of individual amygdala nuclei in the left hemisphere for half of the animals, and in the right hemisphere for the other half (balanced across sexes).

The total numbers of neurons in the main amygdala nuclei were estimated using the optical fractionator method (Gundersen, 1986; West et al., 1991). This design-based method enables an estimation of cell number that is independent of volume estimates. Neuron number was estimated in the right or in the left amygdala only, as for volume measurements. About nine sections per animal (480 $\mu \mathrm{m}$ apart), with the first section selected randomly within the first two sections through the nucleus of interest, were used for neuron counts (Table 1). We used a $100 \times$ PlanFluor oil objective (N.A. 1.30) on a Nikon Eclipse 80i microscope (Nikon Instruments, Melville, NY) linked to PC-based Stereolnvestigator 9.0. The sampling scheme was established to obtain individual estimates of neuron number with estimated coefficients of error (CE) around 0.10 (CE average [neurons] = $0.121)$. This sampling scheme was the same as in our previous study of the adult monkey amygdala (Chareyron et al., 2011), except for the basal nucleus. Section thickness was measured at every other counting site (Table 1).

The volumes of neuronal somas were determined using the nucleator method (Gundersen, 1988). We measured an average of 260 neurons per nucleus, sampled at every counting site during the optical fractionator analysis. Briefly, the nucleator can be used to estimate the mean cross-sectional area and volume of cells. A set of rays emanating from a point randomly chosen within the nucleus is drawn and oriented randomly. The length of the intercept from the point to the cell boundary $(I)$ is measured and the cell volume is obtained by $V=(4 / 3) \times$ $3.1416 \times(\text { mean I })^{3}$. Essentially, this is the formula used to determine the volume of a sphere with a known radius. Note that the nucleator method provides accurate estimates of neuron size when isotropic-uniform random sectioning of brain structures is employed (Gundersen, 1988). In our study, all brains were cut in the coronal plane. Therefore, although estimates of cell size might be impacted by the nonrandom orientation of neurons in the different amygdala nuclei, which could lead to a systematic over- or underestimation of cell size in any given structure, comparisons between cell sizes in the same structure across developmental ages should not be impacted.

The total number of glial cells in the main amygdala nuclei was estimated using the optical fractionator method during neuron counting. Thus, the same sampling scheme used for neuron counts was used for glial cell counts (CE average [astrocytes] $=0.115$, CE average 

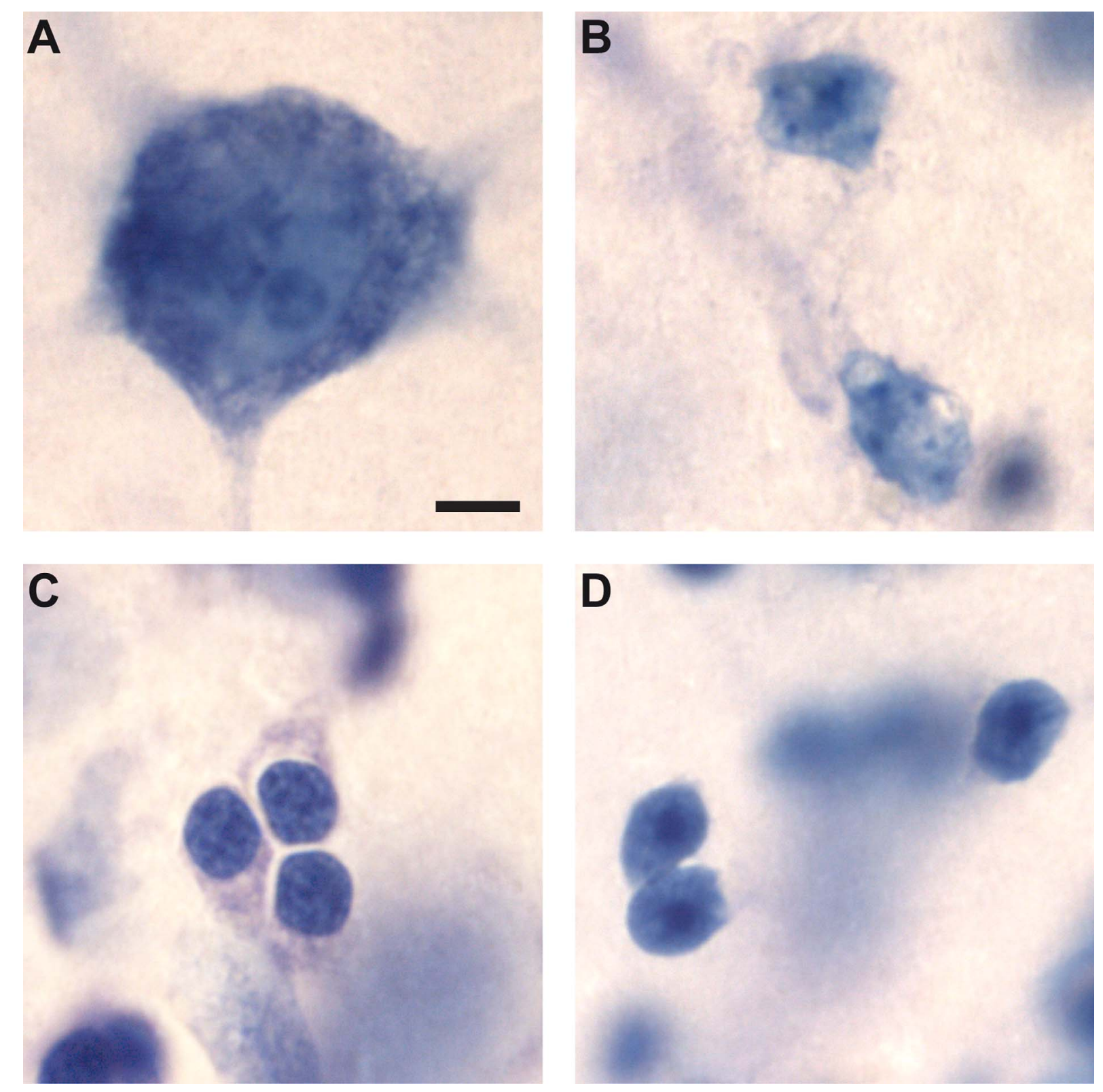

Figure 2. Classification and identification of different cell types in the basal (A-C) and paralaminar (D) nuclei of the monkey amygdala, viewed with a $\times 100$ objective in Nissl-stained, coronal sections cut at $60 \mu \mathrm{m}$. A: Neuron. B: Astrocytes. C: Oligodendrocytes. D: Immature neurons. Scale bar $=5 \mu \mathrm{m}$ in A (applies to all).

[oligodendrocytes] $=0.275$ ). We distinguished neurons, oligodendrocytes, and astrocytes based on morphological criteria identifiable in Nissl preparations (Chareyron et al., 2011) (Fig. 2A-C). We refer the reader to the original publications (Palackal et al., 1993; Grady et al., 2003; Hamidi et al., 2004; Fitting et al., 2008) for detailed descriptions. Briefly, neurons are darkly stained and comprise a single large nucleolus. Astrocytes are relatively smaller in size and exhibit pale staining of the nucleus. Oligodendrocytes are smaller than astrocytes and contain round, darkly staining nuclei that are densely packed with chromatin. Microglia were not counted but could be identified because they have the smallest nucleus, dark staining, and an irregular shape that is often rod-like, oval, or bent (Morris et al., 2008). We also identified a population of immature cells in the paralaminar nucleus (Fig. 2D). These cells were small with round to slightly oval, hyperchromatic nuclei containing distinguishable nucleoli (Yachnis et al., 2000; Bernier et al., 2002; Fudge, 2004).

\section{Photomicrographic production}

Low-magnification photomicrographs were taken with a Leica DFC420 digital camera on a Leica MZ9.5 
stereomicroscope (Leica Microsystems, Wetzlar, Germany). High-magnification photomicrographs were taken with a Leica DFC490 digital camera on a Nikon Eclipse 80i microscope (Nikon Instruments, Tokyo, Japan). Artifacts located outside of the sections were removed and levels were adjusted in Adobe Photoshop CS4, v. 11.0 (Adobe Systems, San Jose, CA) to improve contrast and clarity.

\section{Statistics}

We performed analyses of variance (ANOVAs) with age as a factor on the estimates of the volume, mature neuron number, immature neuron number, astrocyte and oligodendrocyte numbers, and neuronal soma size, as these data were normally distributed. Post-hoc analyses were performed with the Fisher-PLSD test. Significance level was set at $P<0.05$ for all analyses. No consistent sex difference was found for the estimated parameters (data not shown), so data from both sexes were combined for presentation. We also evaluated both left and right amygdala nuclei in a systematic manner (as described above) and no consistent lateralization was found (data not shown). Thus, our findings and all subsequent considerations are valid for, and can be generalized to, both left and right amygdala in both males and females. All sections used in this study were coded to allow blind analysis, and the code was broken only after completion of the analyses (with the exception of the sections from the 59-year-old monkeys that were analyzed first and published in a separate article; Chareyron et al., 2011). All analyses were performed by the same experimenter (L.J.C.).

\section{RESULTS \\ Volumes}

The volumes of the monkey brain, amygdala, and its six main nuclei, at different postnatal ages, are summarized in Table 2. Note that all these volumes were estimated, following brain fixation by perfusion with $4 \%$ paraformaldehyde, using frozen coronal sections cut at $60 \mu \mathrm{m}$ and Nissl-stained with thionin. Due to fixation and processinginduced shrinkage, the resulting volumes are substantially less than the estimates of in vivo brain volumes obtained with MRI technology (see below for discussion). The volume of the brain (telencephalon and diencephalon, bilaterally) differed between age groups $\left(\mathrm{F}_{5,18}=3.254, P\right.$ $=0.029$ ). At birth, brain volume was about $85 \%$ of the adult volume, which was reached by 3 months of age (newborn $<$ all other ages, all $P<0.044$ ). The volume of the whole amygdala also differed between age groups $\left(F_{5,18}=9.308, P<0.001\right)$. At birth, amygdala volume was only $60 \%$ of the adult volume; it was significantly larger at 3 months of age reaching about $82 \%$ of the adult volume (newborn $<3$-months-olds $<$ adults, all $P<$ 0.006).

The volumes of the lateral, basal, and accessory basal nuclei exhibited similar developmental profiles, whereas those of the paralaminar, central, and medial nuclei demonstrated differences (Table 2). At birth, the volume of the lateral nucleus was $66 \%$ of its adult value (Fig. $3 \mathrm{~A}$ ); it was about $91 \%$ of the adult value at 3 months of age $\left(\mathrm{F}_{5,18}=5.025, P=0.005\right.$; newborn $<3$-month-olds, $P=$ $0.003)$. At birth, the volume of the basal nucleus was $55 \%$ of the adult volume (Fig. $3 \mathrm{~A}$ ); it was significantly larger at 3 months of age, reaching about $72 \%$ of the adult volume $\left(\mathrm{F}_{5,18}=7.212, P<0.001\right.$; newborn $<3$-month-olds $<$ adults, all $P<0.035$ ). Similarly, the volume of the accessory basal nucleus was $57 \%$ of its adult volume at birth (Fig. $3 \mathrm{~A}$ ) and was significantly larger at 3 months of age, reaching about $78 \%$ of the adult volume $\left(F_{5,18}=7.697, P\right.$ $<0.001$; newborn $<3$-month-olds $<$ adults, all $P<$ $0.009)$.

In contrast, the paralaminar nucleus was only at $30 \%$ of its adult size at birth (Fig. 3B; $F_{5,18}=16.144, P<0.001$ ); it differed between birth and 6 months of age (when it reached $50 \%$ of adult size; $P=0.035$ ), as well as between 1 year (55\% of adult size) and $5-9$ years of age $(P<$ 0.001 ). The volume of the central nucleus was only $50 \%$ of its adult size at birth (Fig. $3 B$; $F_{5,18}=15.031, P<$ $0.001)$. At 1 year of age, it reached only $57 \%$ of its adult volume ( 1 -year-olds $<5$-9-year-olds, $P<0.001$ ). Finally, although the volume of the medial nucleus increased from $85 \%$ of its adult value at birth, the differences between ages were not significant (Fig. 3B; $F_{5,18}=$ $1.807, P=0.162$ ).

\section{Neuron numbers}

There were no differences in the numbers of neurons estimated at different postnatal ages in five of the main amygdala nuclei in monkeys (Table 2): lateral nucleus $\left(\mathrm{F}_{5,18}=2.240, P=0.095\right)$, basal nucleus $\left(\mathrm{F}_{5,18}=1.178\right.$, $P=0.358)$, accessory basal nucleus $\left(F_{5,18}=0.543, P=\right.$ $0.742)$, central nucleus $\left(F_{5,18}=0.791, P=0.570\right)$, and medial nucleus $\left(F_{5,18}=1.339, P=0.293\right)$.

In contrast, the paralaminar nucleus contained both mature neurons and a pool of morphologically distinct, immature cells (Fig. 2D). The number of mature neurons in this nucleus differed between age groups $\left(F_{5,18}=\right.$ 92.284, $P<0.001$; Table 2). From birth to 1 year of age, the nucleus contained only $15 \%$ of the total number of mature neurons observed in 5-9-year-old monkeys (all other ages $<5$-9-year-olds, all $P<0.001$; Fig. 4A). In order to verify that these differences were not due to differences in the delineation of the nucleus at different ages, especially at its border with the basal nucleus, we 
TABLE 2.

Volume, Cell Numbers, and Neuronal Soma Size in the Main Nuclei of the Monkey Amygdala at Different Ages During Early Postnatal Development

\begin{tabular}{|c|c|c|c|c|c|c|}
\hline & Lateral & Basal & Accessory basal & Paralaminar & Central & Medial \\
\hline \multicolumn{7}{|c|}{ Nuclei volume $\left(\mathrm{mm}^{3}\right)$} \\
\hline Newborn & $25.32 \pm 2.62$ & $25.79 \pm 2.82$ & $13.98 \pm 2.29$ & $2.64 \pm 1.19$ & $4.04 \pm 0.64$ & $4.61 \pm 0.72$ \\
\hline 3-month & $34.86 \pm 4.72$ & $34.08 \pm 8.37$ & $19.11 \pm 3.47$ & $3.27 \pm 1.54$ & $4.08 \pm 0.39$ & $4.59 \pm 0.55$ \\
\hline 6-month & $34.26 \pm 2.75$ & $37.62 \pm 5.08$ & $19.55 \pm 1.81$ & $4.38 \pm 0.90$ & $4.35 \pm 0.64$ & $4.53 \pm 0.40$ \\
\hline 9-month & $32.10 \pm 2.39$ & $35.63 \pm 5.80$ & $20.36 \pm 2.89$ & $4.64 \pm 1.02$ & $4.73 \pm 0.24$ & $4.72 \pm 0.50$ \\
\hline 1-year & $34.73 \pm 6.08$ & $38.36 \pm 3.85$ & $21.48 \pm 1.72$ & $4.85 \pm 0.72$ & $4.65 \pm 0.90$ & $5.09 \pm 0.44$ \\
\hline 5-9-year & $38.40 \pm 3.57$ & $47.15 \pm 2.67$ & $24.38 \pm 2.14$ & $8.84 \pm 0.90$ & $8.15 \pm 1.44$ & $5.42 \pm 0.50$ \\
\hline \multicolumn{7}{|c|}{ Neuron number } \\
\hline Newborn & $1,770,271 \pm 163,872$ & $1,232,759 \pm 220,811$ & $951,634 \pm 196,808$ & $75,024 \pm 15,929$ & $312,095 \pm 22,590$ & $343,439 \pm 32,907$ \\
\hline 3-month & $1,925,343 \pm 123,564$ & $1,328,170 \pm 112,143$ & $959,225 \pm 56,020$ & $61,922 \pm 11,089$ & $274,211 \pm 23,266$ & $322,184 \pm 42,384$ \\
\hline 6-month & $1,865,763 \pm 341,660$ & $1,296,522 \pm 110,063$ & $939,943 \pm 64,479$ & $55,446 \pm 32,295$ & $280,798 \pm 27,801$ & $348,810 \pm 48,376$ \\
\hline 9-month & $1,550,860 \pm 113,446$ & $1,227,670 \pm 159,012$ & $969,833 \pm 62,240$ & $53,343 \pm 36,445$ & $269,968 \pm 29,756$ & $320,119 \pm 63,193$ \\
\hline 1-year & $1,598,605 \pm 284,359$ & $1,347,395 \pm 129,287$ & $881,131 \pm 71,369$ & $60,640 \pm 5,811$ & $300,997 \pm 69,074$ & $316,043 \pm 9,063$ \\
\hline 5-9-year & $1,592,284 \pm 128,381$ & $1,445,882 \pm 138,651$ & $885,352 \pm 101,469$ & $408,051 \pm 49,453$ & $297,079 \pm 30,889$ & $282,622 \pm 25,053$ \\
\hline \multicolumn{7}{|c|}{ Astrocyte number } \\
\hline Newborn & $1,075,160 \pm 199,787$ & $1,147,166 \pm 88,636$ & $811,074 \pm 113,488$ & $83,872 \pm 27,587$ & $294,217 \pm 29,384$ & $284,953 \pm 28,999$ \\
\hline 3-month & $1,348,781 \pm 177,464$ & $1,280,084 \pm 205,464$ & $825,492 \pm 58,221$ & $147,255 \pm 35,000$ & $253,739 \pm 31,139$ & $272,562 \pm 44,068$ \\
\hline 6-month & $1,150,751 \pm 154,674$ & $1,202,133 \pm 242,384$ & $720,950 \pm 60,125$ & $142,127 \pm 26,101$ & $265,206 \pm 41,489$ & $246,904 \pm 35,274$ \\
\hline 9-month & $1,029,207 \pm 15,720$ & $1,187,168 \pm 195,565$ & $779,742 \pm 85,046$ & $116,953 \pm 41,715$ & $280,819 \pm 50,842$ & $249,895 \pm 77,082$ \\
\hline 1-year & $1,049,401 \pm 198,033$ & $1,328,610 \pm 210,249$ & $804,816 \pm 12,100$ & $150,934 \pm 26,169$ & $295,778 \pm 50,687$ & $291,903 \pm 45,238$ \\
\hline 5-9-year & $1,044,198 \pm 64,819$ & $1,237,921 \pm 86,478$ & $701,739 \pm 23,552$ & $191,762 \pm 28,505$ & $276,106 \pm 15,546$ & $235,419 \pm 17,978$ \\
\hline \multicolumn{7}{|c|}{ Oligodendrocyte number } \\
\hline Newborn & $65,897 \pm 116,192$ & $18,973 \pm 37,946$ & $1,668 \pm 2,013$ & $602 \pm 1,205$ & $815 \pm 941$ & $0 \pm 0$ \\
\hline 3-month & $88,714 \pm 34,991$ & $94,902 \pm 45,779$ & $29,149 \pm 19,368$ & $11,492 \pm 5,919$ & $31,473 \pm 7,393$ & $13,323 \pm 13,275$ \\
\hline 6-month & $208,438 \pm 128,030$ & $228,086 \pm 68,389$ & $72,778 \pm 37,834$ & $7,644 \pm 6,015$ & $64,864 \pm 14,405$ & $32,680 \pm 16,572$ \\
\hline 9-month & $237,718 \pm 129,714$ & $267,359 \pm 104,294$ & $103,735 \pm 50,864$ & $13,359 \pm 9,665$ & $84,303 \pm 28,442$ & $41,880 \pm 22,442$ \\
\hline 1-year & $355,195 \pm 114,080$ & $384,490 \pm 107,272$ & $153,342 \pm 51,464$ & $17,538 \pm 10,532$ & $100,881 \pm 35,533$ & $45,027 \pm 24,144$ \\
\hline 5-9-year & $1,112,480 \pm 131,622$ & $1,247,140 \pm 139,668$ & $572,196 \pm 82,235$ & $96,422 \pm 23,397$ & $210,656 \pm 28,544$ & $102,661 \pm 13,889$ \\
\hline \multicolumn{7}{|c|}{ Neuronal soma volume average $\left(\mu \mathrm{m}^{3}\right)$} \\
\hline Newborn & $1,536 \pm 95$ & $2,419 \pm 226$ & $1,646 \pm 131$ & $740 \pm 124$ & $1,265 \pm 110$ & $1,089 \pm 152$ \\
\hline 3-month & $1,675 \pm 375$ & $2,492 \pm 513$ & $1,691 \pm 376$ & $1,005 \pm 219$ & $1,233 \pm 247$ & $1,015 \pm 80$ \\
\hline 6-month & $1,694 \pm 177$ & $2,555 \pm 354$ & $1,826 \pm 124$ & $1,524 \pm 263$ & $1,328 \pm 122$ & $1,067 \pm 101$ \\
\hline 9-month & $1,679 \pm 205$ & $2,567 \pm 333$ & $1,822 \pm 189$ & $1,058 \pm 418$ & $1,483 \pm 200$ & $1,191 \pm 195$ \\
\hline 1-year & $1,533 \pm 112$ & $2,268 \pm 209$ & $1,707 \pm 97$ & $1,385 \pm 489$ & $1,194 \pm 117$ & $1,129 \pm 61$ \\
\hline 5-9-year & $1,433 \pm 158$ & $2,073 \pm 99$ & $1,804 \pm 92$ & $1,470 \pm 87$ & $1,374 \pm 69$ & $1,176 \pm 27$ \\
\hline \multicolumn{7}{|c|}{$\%$ of nucleus volume occupied by neuronal somas } \\
\hline Newborn & $10.77 \pm 0.93$ & $11.49 \pm 1.24$ & $11.25 \pm 1.86$ & $3.08 \pm 2.85$ & $9.85 \pm 1.01$ & $8.21 \pm 1.53$ \\
\hline 3-month & $9.18 \pm 1.14$ & $9.74 \pm 0.35$ & $8.44 \pm 0.52$ & $2.49 \pm 1.63$ & $8.31 \pm 1.70$ & $7.27 \pm 1.78$ \\
\hline 6-month & $9.19 \pm 1.51$ & $8.83 \pm 1.05$ & $8.85 \pm 1.25$ & $2.01 \pm 1.18$ & $8.70 \pm 1.62$ & $8.38 \pm 2.15$ \\
\hline 9-month & $8.11 \pm 0.97$ & $8.86 \pm 0.91$ & $8.71 \pm 0.50$ & $1.22 \pm 0.99$ & $8.52 \pm 1.73$ & $7.92 \pm 0.72$ \\
\hline 1-year & $7.05 \pm 0.40$ & $7.96 \pm 0.63$ & $7.01 \pm 0.52$ & $1.72 \pm 0.57$ & $7.67 \pm 0.60$ & $7.04 \pm 0.65$ \\
\hline 5-9-year & $5.96 \pm 0.79$ & $6.34 \pm 0.32$ & $6.54 \pm 0.41$ & $6.80 \pm 0.70$ & $5.06 \pm 0.40$ & $6.16 \pm 0.63$ \\
\hline
\end{tabular}




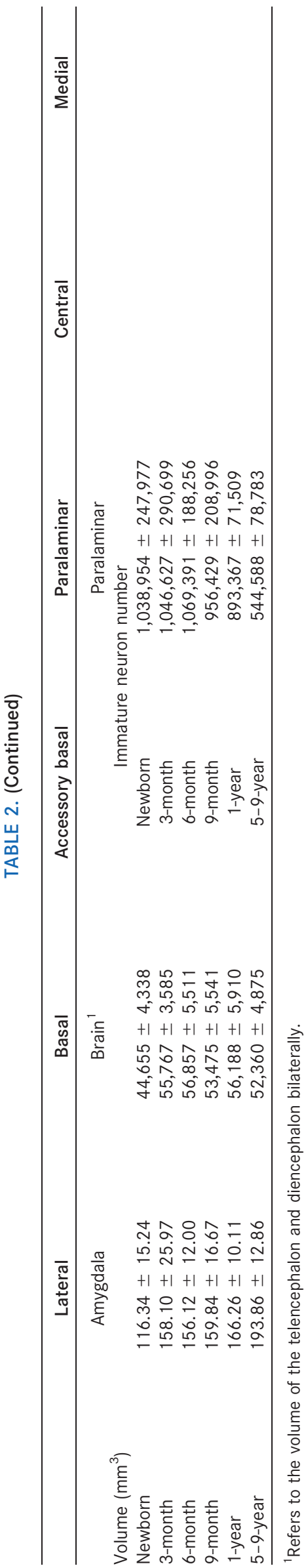

evaluated the differences in neuron numbers summed across both nuclei, i.e., the sum of the neurons in the paralaminar and basal nuclei. We found that when the two nuclei were grouped together, there were similar differences between ages $\left(F_{5,18}=7.364, P<0.001\right.$; all other ages $<5$-9-year-olds, all $P<0.001$ ) as when the paralaminar nucleus was evaluated alone; as noted above, the neuron number in the basal nucleus alone did not differ in this way. The increase of about 350,000 mature neurons in the paralaminar nucleus was paralleled by the disappearance of an equivalent number of morphologically distinct, presumably immature neurons $\left(\mathrm{F}_{5,18}=\right.$ 3.965, $P=0.013$; all other ages $>5$-9-year-olds, all $P<$ 0.023 ; Table 2; Fig. 4A). It is important to note that the sum of the number of mature neurons and immature cells observed in the paralaminar nucleus did not differ between ages $\left(F_{5,18}=0.624, P=0.684\right)$. This supports the idea that these morphologically distinct cells are immature neurons that are present in the paralaminar nucleus at birth but mature after 1 year of age.

\section{Astrocyte numbers}

There were no significant differences in the numbers of astrocytes found in five of the main amygdala nuclei of monkeys at different postnatal ages (Table 2): lateral nucleus $\left(F_{5,18}=2.562, P=0.064\right)$, basal nucleus $\left(F_{5,18}=\right.$ $0.526, P=0.754)$, accessory basal nucleus $\left(F_{5,18}=\right.$ 2.251, $P=0.093)$, central nucleus $\left(\mathrm{F}_{5,18}=0.720, P=\right.$ $0.617)$, and medial nucleus $\left(F_{5,18}=1.011, P=0.440\right)$.

In contrast, the number of astrocytes in the paralaminar nucleus differed between age groups $\left(F_{5,18}=5.308\right.$, $P=0.004$; Fig. 4); it was lower in newborn, as compared to 3-month-old monkeys $(P=0.01)$. The numbers of astrocytes in the paralaminar nucleus at the time points between 3 months and 1 year of age were lower than in 5-9-year-old monkeys (3-month, 6-month, 9-month, 1year $<5$-9-year; all $P<0.007$ ).

\section{Oligodendrocyte numbers}

The numbers of oligodendrocytes differed between age groups in the six main amygdala nuclei (Table 2; Fig. 5). For the lateral nucleus (Fig. 5A; $F_{5,18}=46.777, P<$ 0.001 ), newborns had fewer cells than 9-month-olds and older (all $P<0.047$ ) and 1-year-olds had fewer cells than 5-9-year-olds $(P<0.001)$. In the basal nucleus (Fig. 5B; $\left.\mathrm{F}_{5,18}=95.712, P<0.001\right)$, newborns had fewer cells than 6-month-olds, which had fewer than 1-year-olds, which again had fewer than 5 -9-year-olds (all $P<0.026$ ). For the accessory basal nucleus (Fig. 5C; $F_{5,18}=77.443$, $P<0.001$ ), newborns had fewer cells than 9-month-olds and older (all $P<0.008$ ) and 1-year-olds had fewer oligodendrocytes than 5 -9-year-olds $(P<0.001)$. In the paralaminar nucleus (Fig. 5D; $F_{5,18}=37.087, P<0.001$ ), all 

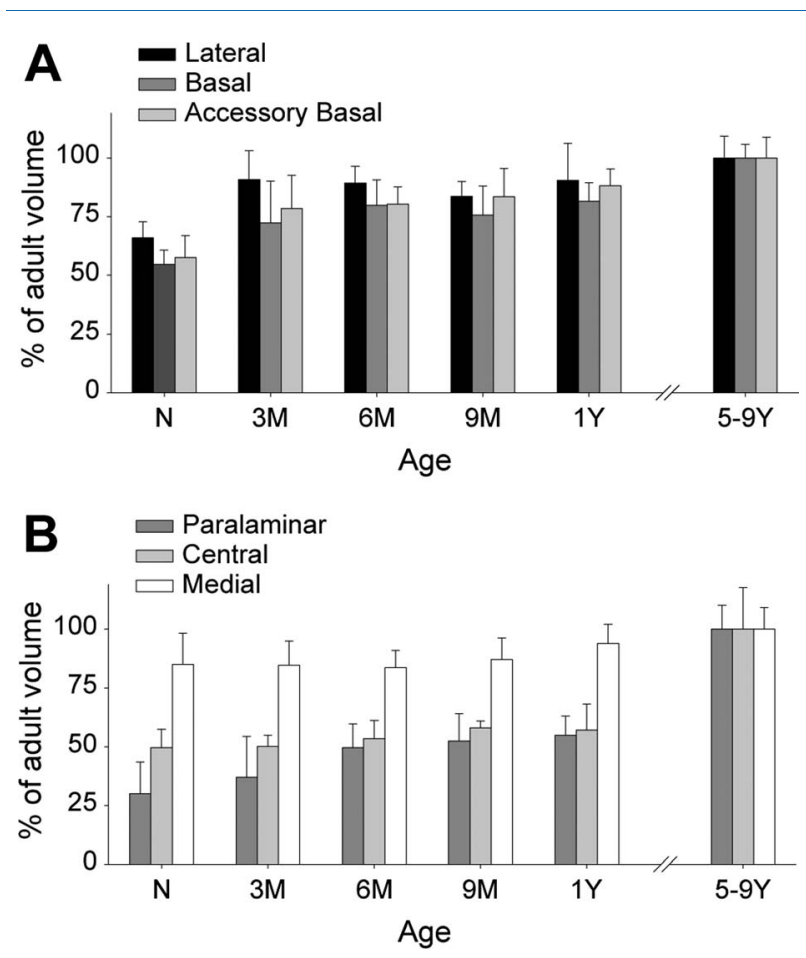

Figure 3. Volumes of the main nuclei of the monkey amygdala at different ages during early postnatal development (expressed as a percentage of the volume of the structure observed in 5-9year-old monkeys: average $\pm \mathrm{SD}$ ). A: Lateral, basal, and accessory basal nuclei. B: Paralaminar, central, and medial nuclei. N: newborns; 3M: 3-month-olds; 6M: 6-month-olds; 9M: 9-month-olds; 1Y: 1-year-olds; 5-9Y: 5-9-year-olds.

younger ages had fewer oligodendrocytes than 5-9-yearolds (all $P<0.001$ ). For the central nucleus (Fig. 5E; $\mathrm{F}_{5,18}$ $=40.163, P<0.001$ ), newborns had fewer oligodendrocytes than 6-month-olds, which had fewer cells than 1year-olds, which had fewer cells than 5-9-year-olds (all $P$ $<0.039$ ). Finally, in the medial nucleus (Fig. 5F; $F_{5,18}=$ 17.524, $P<0.001$ ), newborns had fewer cells than 6month-olds $(P=0.014)$ and 1 -year-olds had fewer cells than 5-9-year-olds $(P<0.001)$.

\section{Neuron soma size}

We did not find any age-related differences in average neuronal soma size in five of the main amygdala nuclei (Table 2; Fig. 6): lateral nucleus $\left(\mathrm{F}_{5,18}=1.052, P=\right.$ $0.418)$, basal nucleus $\left(F_{5,18}=1.468, P=0.249\right)$, accessory basal nucleus $\left(\mathrm{F}_{5,18}=0.631, P=0.679\right)$, central nucleus $\left(F_{5,18}=1.822, P=0.159\right)$, and medial nucleus $\left(\mathrm{F}_{5,18}=1.309, P=0.304\right)$.

In contrast, average neuronal soma size differed between age groups in the paralaminar nucleus (Fig. 7; $\mathrm{F}_{5,18}=4.176, P=0.011$ ); newborns had smaller neurons than 6-month-olds and 1-year-olds (all $P<0.008$ ) and 3month-olds had smaller neurons than 5 -9-year-olds $(P=$
0.044). The percentage of paralaminar neurons with a soma volume above $1,500 \mu^{3}$ (the average adult neuronal soma volume) differed between ages within the first year of postnatal life $\left(\mathrm{F}_{4,15}=4.921, P=0.01\right)$. In newborns, this percentage was only $6.0 \%$; it increased significantly $(P=0.004)$ to $38.8 \%$ in 1 -year-olds. These differences were linked to the maturation of neurons already present in the paralaminar nucleus at birth (Fig. 4; as described above).

\section{Volume and oligodendrocyte numbers}

During the first 3 months of postnatal life, amygdala nuclei exhibited increases in volume that were not related to any changes in the cellular processes evaluated in the current study. This indicates that the increased volume was due to an increase in neuropil volume. Between 3 months and 5-9 years of age, increases in the volumes of individual amygdala nuclei were not correlated with the numbers of neurons or astrocytes nor with the volume of neuronal soma. In contrast, after 3 months of age the volume of the whole amygdala correlated with the total number of oligodendrocytes (volume $=96.627+0.0000108$ $\times$ oligodendrocyte number; $\mathrm{R}^{2}=0.58 ; \mathrm{F}_{1,18}=25.349 ; P$ $<0.001)$. A significant linear relationship between volume and oligodendrocyte number was observed for all nuclei, except for the medial nucleus: lateral nucleus (volume $=32.747+0.0000053 \times$ oligodendrocyte number; $\mathrm{R}^{2}=0.23 ; \mathrm{F}_{1,18}=5.636 ; P=0.029$; Fig. 8A), basal nucleus (volume $=33.679+0.000011 \times$ oligodendrocyte number; $\mathrm{R}^{2}=0.49 ; \mathrm{F}_{1,18}=17.523 ; P<0.001$; Fig. 8B), accessory basal nucleus (volume $=19.259+0.0000092$

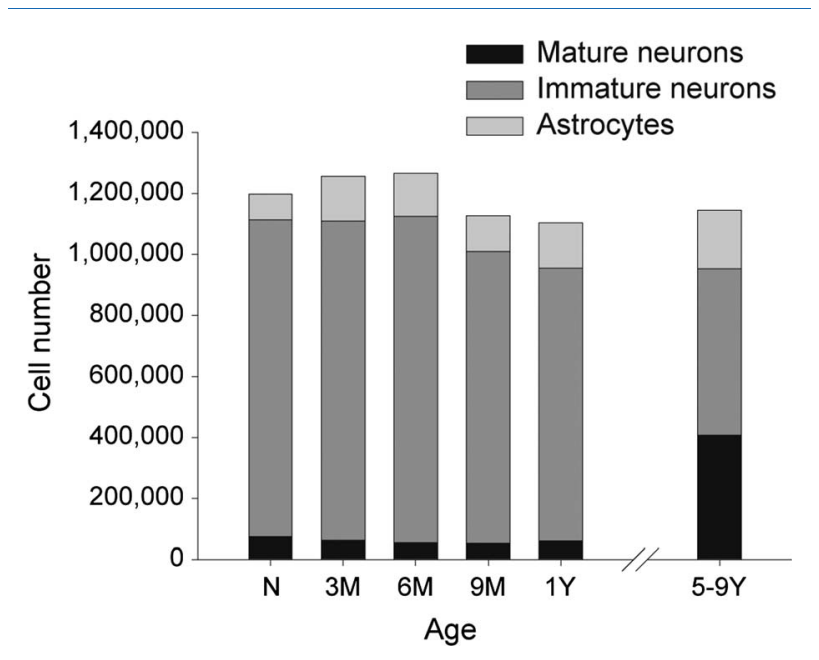

Figure 4. Numbers of astrocytes, mature neurons, and immature cells in the paralaminar nucleus of the monkey amygdala at different ages during postnatal development. Note that the total number of neurons (mature+immature) remains constant throughout postnatal development. N: newborns; 3M: 3-month-olds; 6M: 6-montholds; 9M: 9-month-olds; 1Y: 1-year-olds; 5-9Y: 5-9-year-olds. 

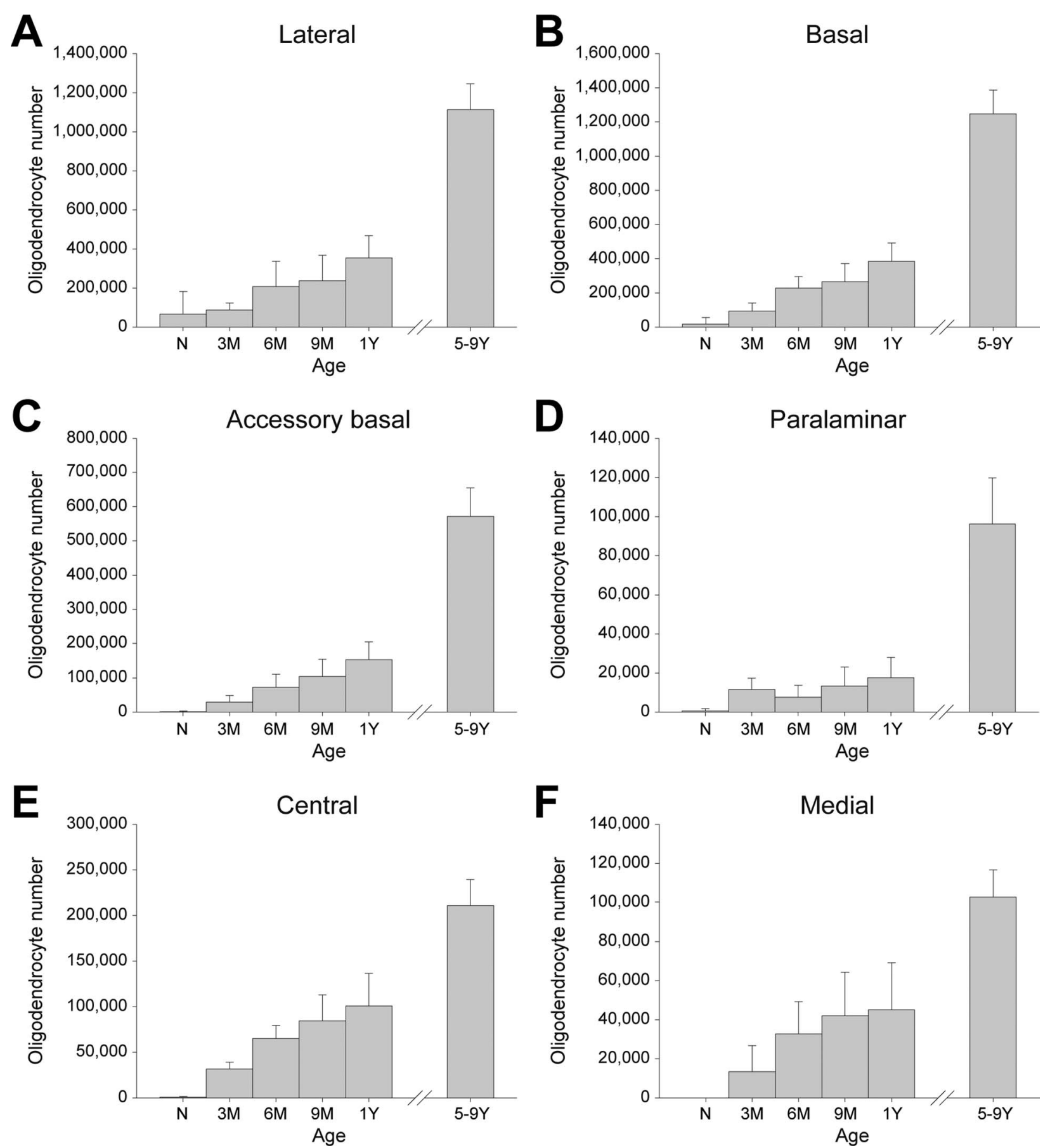

Figure 5. Numbers of oligodendrocytes in the six main nuclei of the monkey amygdala at different ages during early postnatal development. A: Lateral. B: Basal. C: Accessory basal. D: Paralaminar. E: Central. F: Medial. Error bars: \pm SD. N: newborns; 3M: 3-month-olds; 6M: 6-month-olds; 9M: 9-month-olds; 1Y: 1-year-olds; 59Y: 59-year-olds.

$\times$ oligodendrocyte number; $\mathrm{R}^{2}=0.42 ; \mathrm{F}_{1,18}=13.129 ; P$ $=0.002$; Fig. $8 \mathrm{C}$ ), paralaminar nucleus (volume $=3.782$ $+0.0000482 \times$ oligodendrocyte number; $R^{2}=0.65$ $\mathrm{F}_{1,18}=34.620 ; P<0.001$; Fig. 8D), central nucleus (volume $=2.904+0.0000232 \times$ oligodendrocyte number; $\left.\mathrm{R}^{2}=0.81 ; \mathrm{F}_{1,18}=76.982 ; P<0.001 ; \mathrm{Fig} .8 \mathrm{E}\right)$, medial nucleus (volume $=4.548+0.00000686 \times$ oligodendrocyte number; $\mathrm{R}^{2}=0.18 ; \mathrm{F}_{1,18}=4.169 ; P=0.056$; Fig. $8 \mathrm{~F}$ ). Overall, these data suggest that increases in volume after 3 months of postnatal life are linked, at least in part, to increases in oligodendrocyte numbers and the myelination of fibers within the amygdala. Interestingly, this relation was strongest for the central nucleus. Other changes, including the maturation of dendritic arborization, are also likely to contribute to postnatal volumetric changes. Analysis 


\section{Lateral}
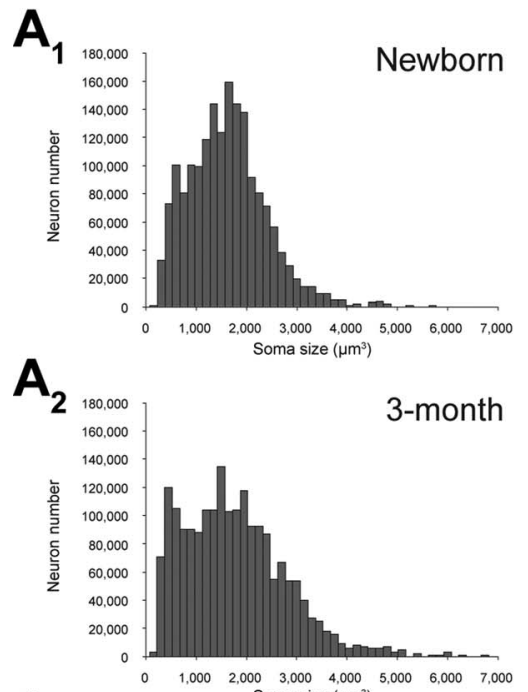

$\mathbf{A}_{3}$

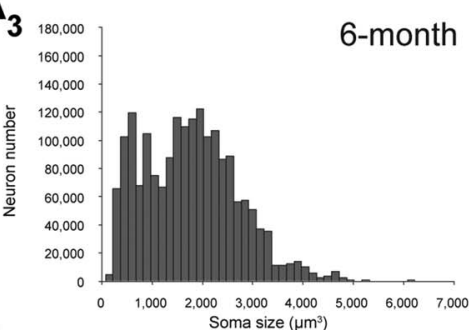

$\mathbf{A}_{4}$

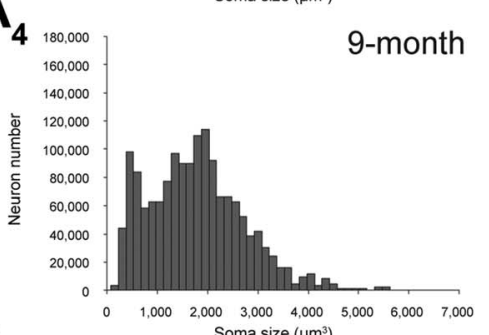

$\mathbf{A}_{5}$

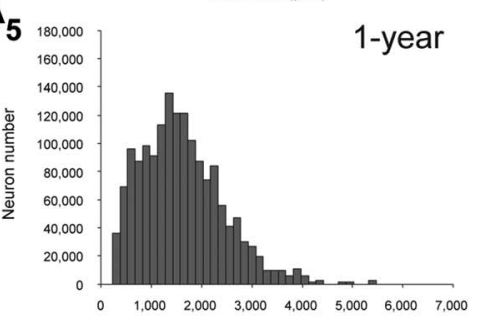

$\mathbf{A}_{6}$

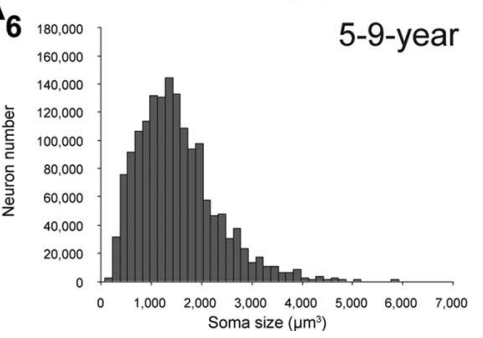

Basal

$\mathbf{B}_{1}$

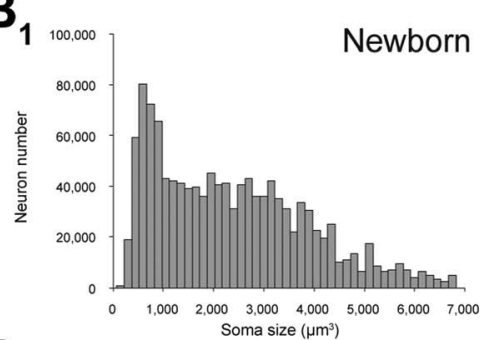

$B_{2}$

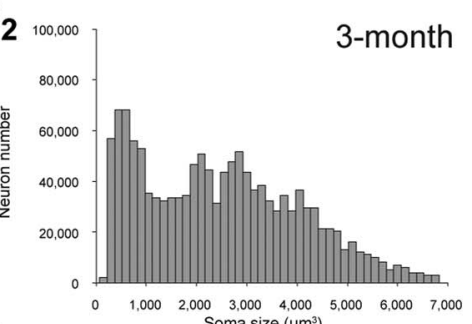

$B_{3}$

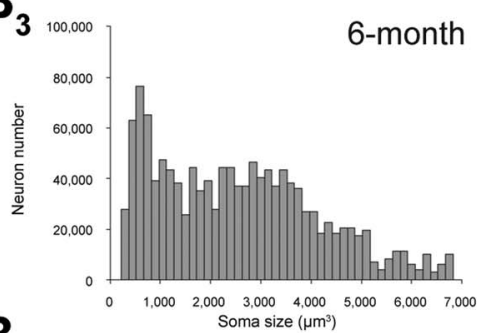

B.

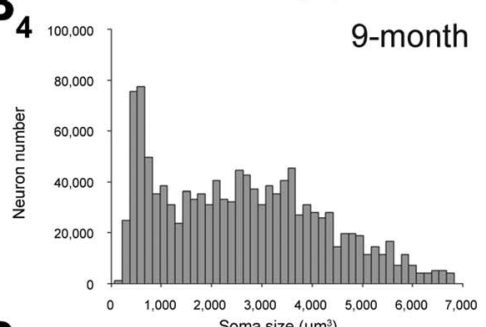

$\mathbf{B}_{5}$

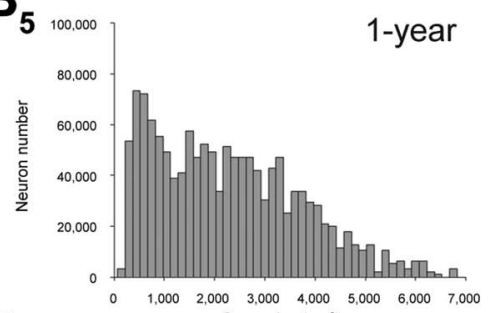

B 6

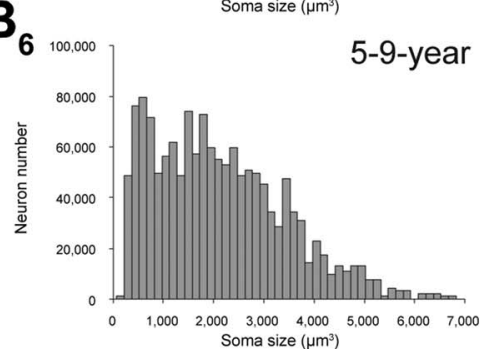

Accessory Basal

$C_{1}$

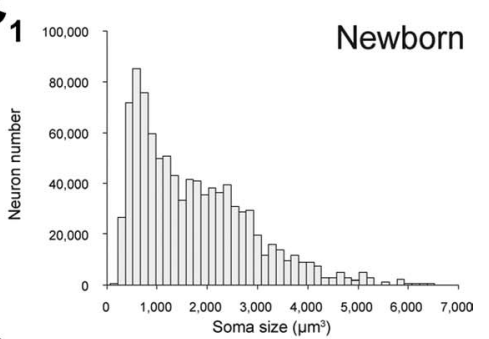

$\mathrm{C}_{2}$

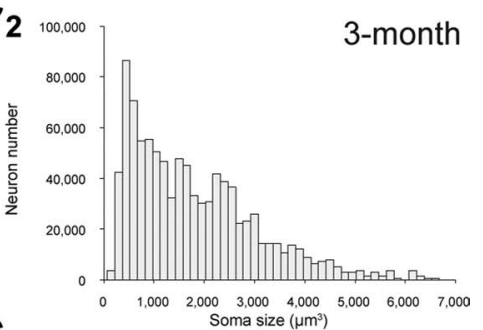

$\mathrm{C}_{3}$

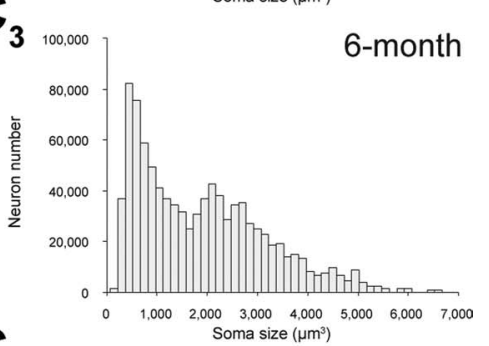

$\mathrm{C}_{4}$
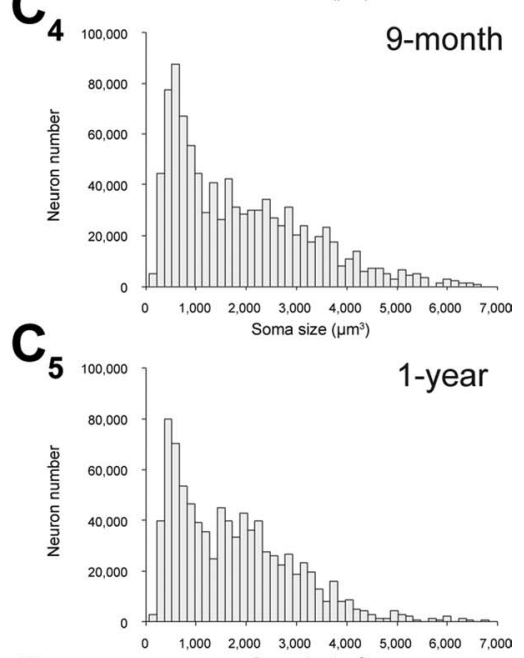

$\mathbf{C}_{6}$

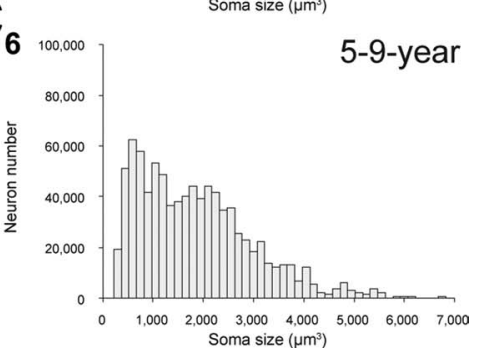

Figure 6. Neuronal soma size in the five main nuclei of the monkey amygdala at different ages during early postnatal development. $A_{1}-$ $A_{6}$ : Lateral. $B_{1}-B_{6}$ : Basal. $C_{1}-C_{6}$ : Accessory basal. $D_{1}-D_{6}$ : Central. $E_{1}-E_{6}$ : Medial. 
Central

D

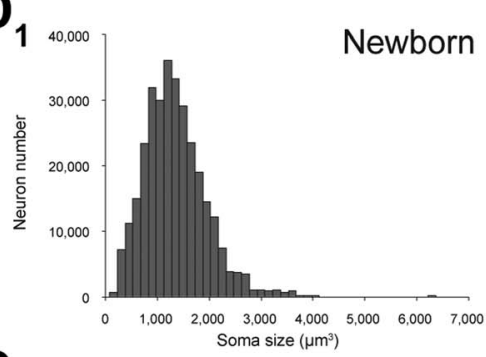

$\mathbf{D}_{2}$

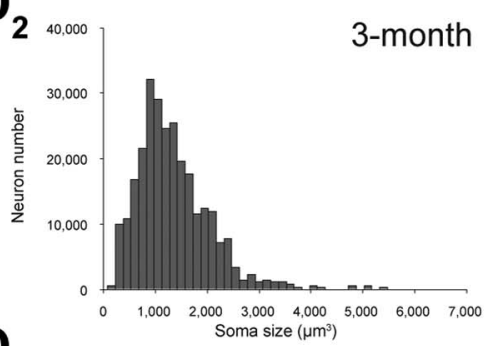

$\mathbf{D}_{3}$

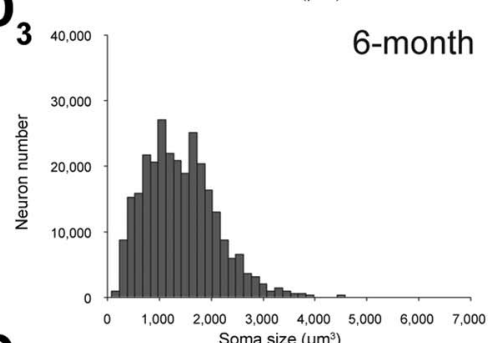

$D_{4}$
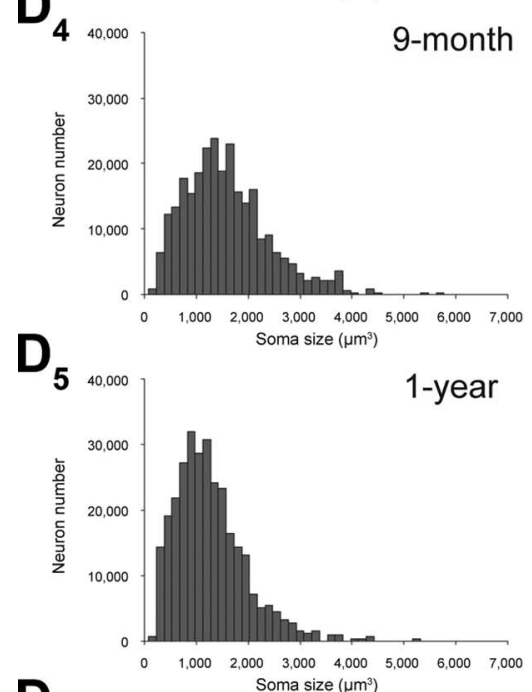

$D_{6}$

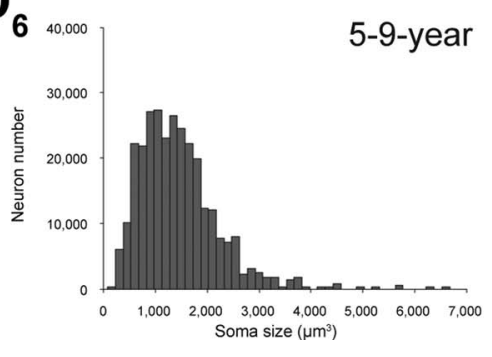

Medial

$E_{1}$
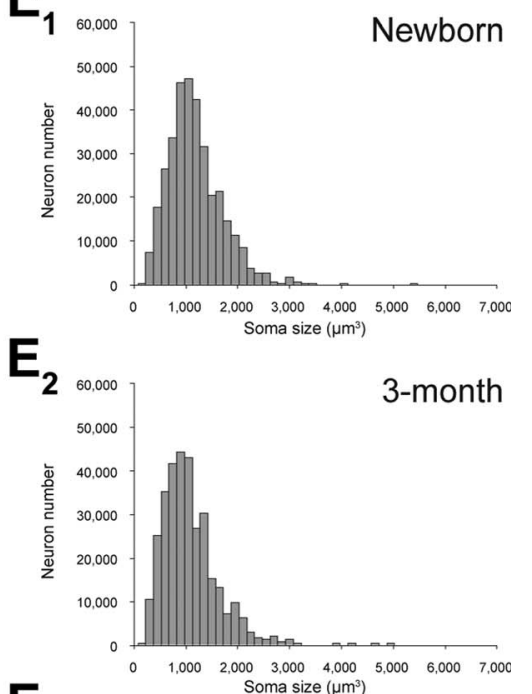

$\mathbf{E}_{3}$
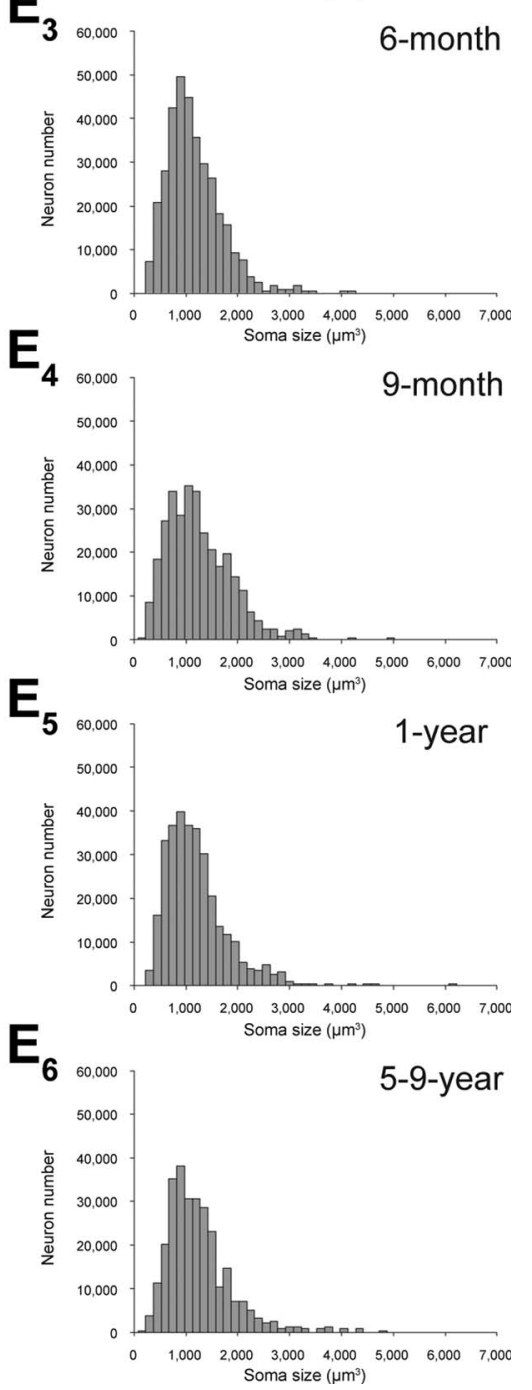

Figure 6. (Continued) 

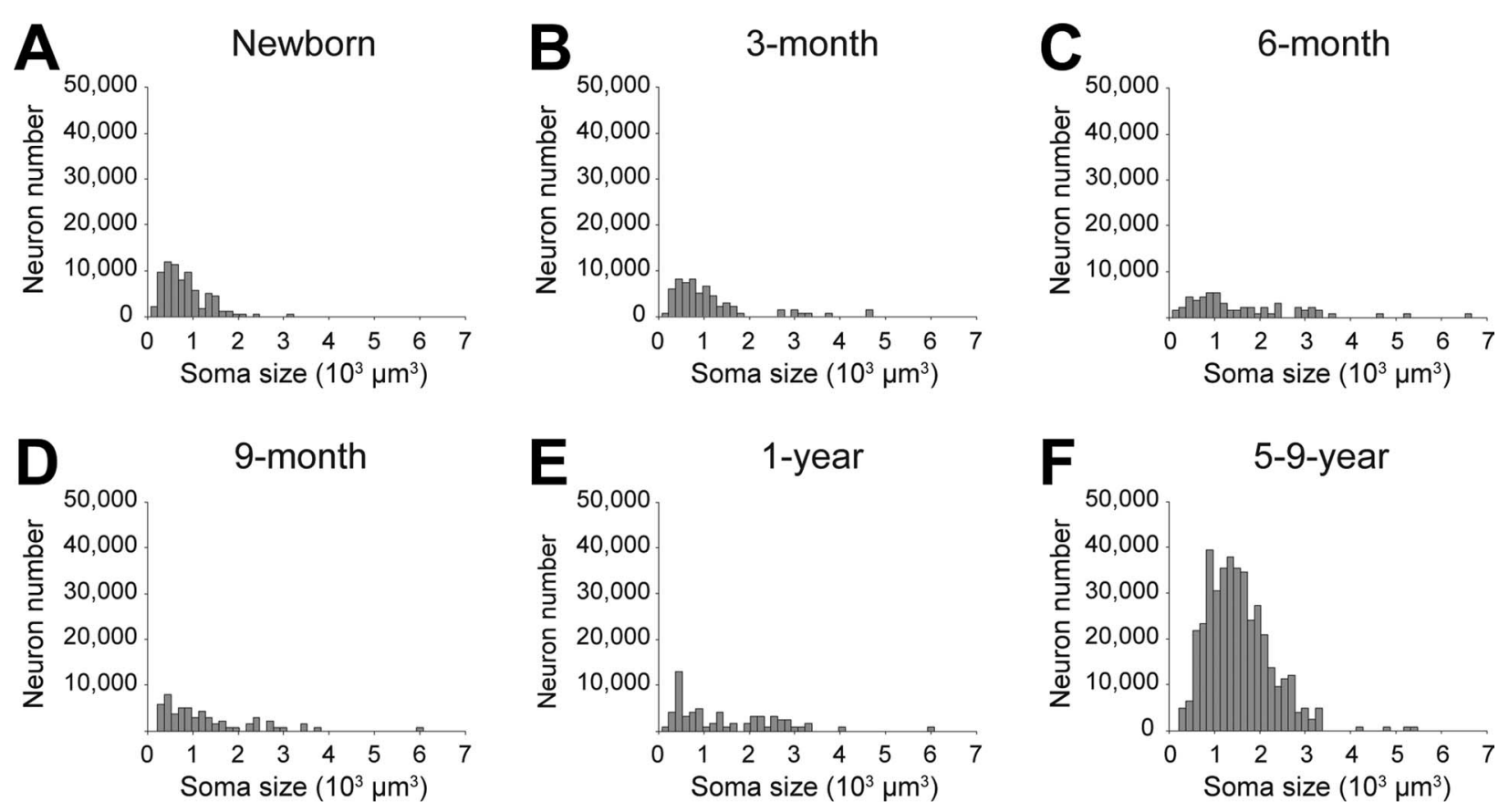

Figure 7. Neuronal soma size in the paralaminar nucleus of the monkey amygdala at different ages during early postnatal development. A: Newborns. B: 3-month-olds. C: 6-month-olds. D: 9-month-olds. E: 1-year-olds. F: 5-9-year-olds.

of postnatal dendritic maturation in several nuclei of the rhesus monkey is currently being undertaken.

\section{DISCUSSION}

The goal of the present study was to provide quantitative neuroanatomical information about the cellular postnatal maturation of the rhesus monkey amygdala, including when the volumes and cell numbers of its six main nuclei (i.e., lateral, basal, accessory basal, paralaminar, central, and medial) reach an adult-like state. Our three major findings were: 1) amygdala nuclei exhibited different developmental profiles; 2) neuronal soma size and neuron and astrocyte numbers did not vary after birth in five of the six main amygdala nuclei, whereas the numbers of oligodendrocytes increased continuously in all nuclei from birth to beyond 1 year of age; 3 ) at birth, the paralaminar nucleus was comprised of a group of mature neurons and a group of immature neurons that developed after 1 year of age.

There is, to our knowledge, no published information on the postnatal maturation of the monkey or human amygdala at the cellular level. We therefore compare our results to noninvasive MRI studies carried out in primates, including monkeys and humans, as well as to previous work carried out at the cellular level in rats and rabbits. Our systematic, quantitative findings provide detailed information regarding the cellular changes underlying the different developmental profiles of distinct amygdala nuclei in monkeys, which are largely consistent with, and expand upon, the findings of previous reports in other species.

\section{Technical considerations}

First, it is important to consider that age-related, differential shrinkage of brain tissue during processing cannot explain the age differences in the volumes of distinct amygdala nuclei that we observed. Although the average thickness of processed sections was lower in newborn cases ( $9.6 \mu \mathrm{m}$ or $16 \%$ of the cutting thickness), as compared to all other ages $(13.0 \mu \mathrm{m}$ or $22 \%$ of the cutting thickness), volume estimates were based on the cutting section interval $(240 \mu \mathrm{m}$ for individual amygdala nuclei). The impact of age-dependent differential shrinkage in the $x$ - and $y$-plane of frozen brain sections is minimal and likely minor, as compared with shrinkage in the z-plane (Carlo and Stevens, 2011). In addition, our data derived from estimates made on frozen sections cut at $60 \mu \mathrm{m}$ and Nissl-stained with thionin are consistent with the direction and magnitude of changes in the volume of the amygdala estimated in vivo with noninvasive MRI technology (even though estimates based on histological preparations are consistently smaller by about $40 \%$ in mature individuals than in vivo estimates [i.e., telencephalon+diencephalon in 5-9-year-old monkeys: $52,360 \mathrm{~mm}^{3}$ (present study) vs. whole brain 

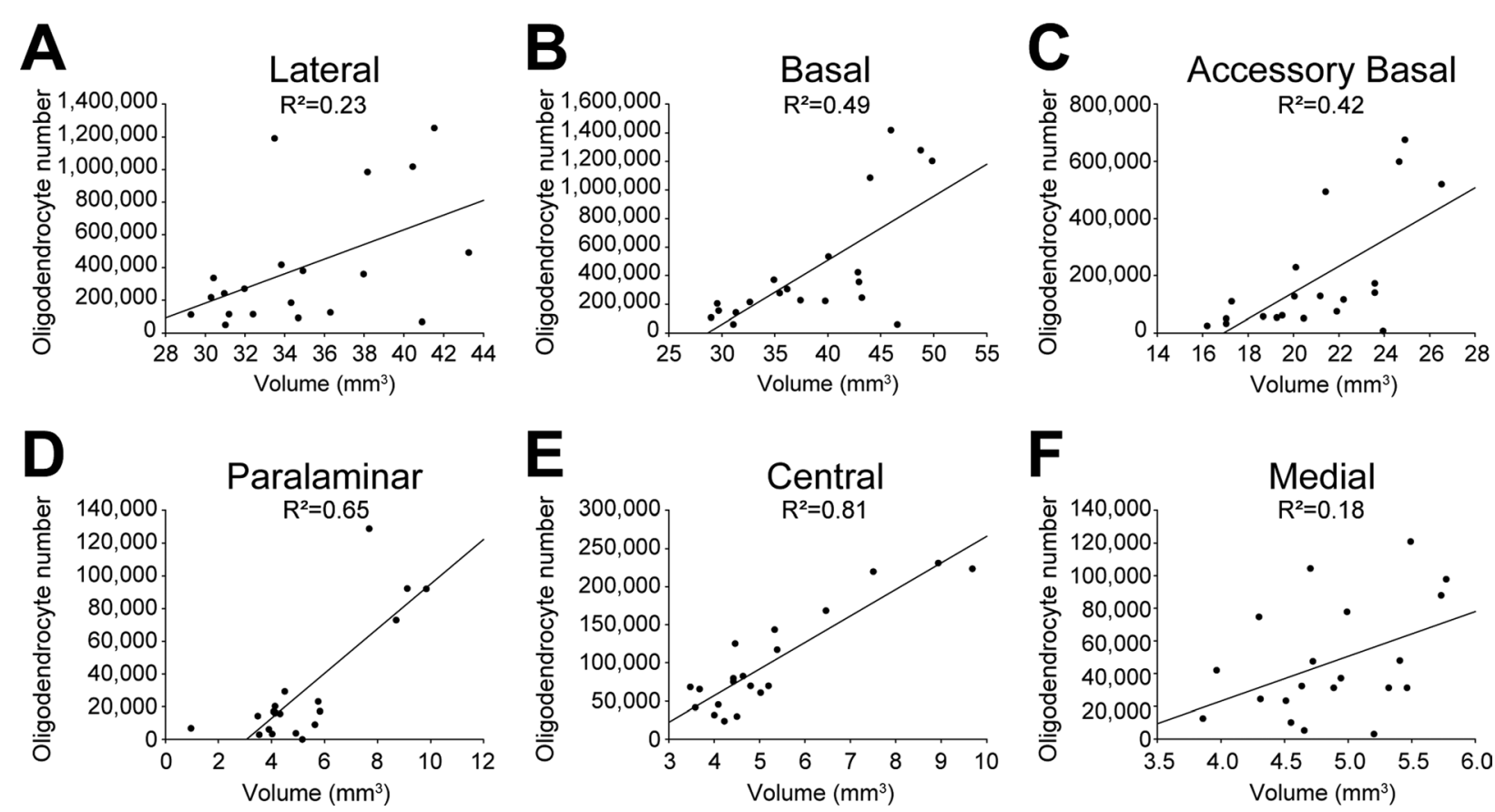

Figure 8. Relationship between oligodendrocyte number and volume of the main amygdala nuclei of monkeys from 3 months to 1 year of age and at $5-9$ years of age. A: Lateral (volume $=32.747+\left(0.0000053 \times\right.$ oligodendrocyte number); $\mathrm{R}^{2}=0.23 ; \mathrm{F}_{1,18}=5.636 ; P=$ 0.029). B: Basal (volume $=33.679+\left(0.000011 \times\right.$ oligodendrocyte number); $\left.R^{2}=0.49 ; F_{1,18}=17.523 ; P<0.001\right)$. C: Accessory basal (volume $=19.259+\left(0.0000092 \times\right.$ oligodendrocyte number); $\left.R^{2}=0.42 ; F_{1,18}=13.129 ; P=0.002\right)$. D: Paralaminar (volume $=3.782+$ $\left(0.0000482 \times\right.$ oligodendrocyte number); $\left.\mathrm{R}^{2}=0.65 ; \mathrm{F}_{1,18}=34.620 ; P<0.001\right)$. E: Central (volume $=2.904+(0.0000232 \times$ oligodendrocyte number); $\left.\mathrm{R}^{2}=0.81 ; \mathrm{F}_{1,18}=76.982 ; P<0.001\right)$. F: Medial (volume $=4.548+\left(0.00000686 \times\right.$ oligodendrocyte number); $\mathrm{R}^{2}=$ $\left.0.18 ; \mathrm{F}_{1,18}=4.169 ; P=0.056\right)$.

(cerebellum+brainstem) in 8-12-year-old monkeys: $87,080 \mathrm{~mm}^{3}$ (Scott et al., submitted); see below for further discussion]). Moreover, since we observed different patterns of postnatal development for distinct amygdala nuclei it is unlikely that differential shrinkage impacts the suggestions regarding the relative development of specific circuits and processes that can be derived from our volumetric data. Importantly, cell counts are not impacted by differential shrinkage, as the optical fractionator technique provides estimates of cell numbers that are independent of volume estimates. Similarly, estimates of neuronal soma size are likely not significantly affected, as we did not observe any significant developmental increase (except for the paralaminar nucleus) in neuronal soma size.

\section{Brain and amygdala volumes}

The rapid increase in brain volume that we observed during the first 3 months of life in rhesus monkeys is consistent with previous findings of MRI studies in monkeys (Malkova et al., 2006; Payne et al., 2010; Scott et al., submitted) and humans (Pfefferbaum et al., 1994; Giedd et al., 1999; Courchesne et al., 2000; Knickmeyer et al., 2008).
In rhesus monkeys, Malkova et al. (2006) reported that brain volume is $64 \%$ that of the young adult at 1 week of age. The most substantial increase occurs between 1 week and 2 months followed by lesser increases until 3 years of age. Similarly, Payne et al. (2010) reported that at 1 week of age brain volume is about $60 \%$ that of the 2 year-old monkey. Most recently, Scott et al. (submitted) found that the average brain volume of 1-week-old monkeys is $66 \%$ that of 9-12-year-olds. By 3 months of age, brain volume has reached $85 \%$ of its adult value, and by 1 year it has reached adult volume. These MRI findings, which are largely consistent, differ from our brain volume estimates in perfusion-fixed tissue (Table 2). This difference might be due to the shrinkage that occurs during perfusion-fixation and freezing of the monkey brains, before they are cut and the sections are stained. In contrast to the shrinkage in the $z$-axis produced during the processing of individual $60-\mu \mathrm{m}$ sections, which is greater in newborns as compared to older ages (see above), surprisingly, overall brain shrinkage following perfusion and freezing processes appears to be greater in older monkeys (postmortem brain volume is $61 \%$ of the in vivo volume in 5-9-year-olds) than in younger monkeys (postmortem brain volume is $77 \%$ of the in vivo volume in 
newborns (Table 2). At this time, we are at a loss to explain such age-dependent differential shrinkage. This suggests that the developmental increases in volume of individual amygdala nuclei that we estimated from postmortem material might be even larger in live subjects. Importantly, the relatively greater (in relation to overall brain size) enlargement of the monkey amygdala that we observed between birth and 3 months of age is in agreement with reported data on amygdala development based on MRI analyses (Payne et al., 2010).

Our data in monkeys are also consistent with MRI studies performed in humans that show a linear increase in size of the amygdala of about $75 \mathrm{~mm}^{3}$ per year from 18 to 59 months of age (Mosconi et al., 2009; Ostby et al., 2009), which continues into young adulthood at about 70 $\mathrm{mm}^{3}$ per year (Giedd et al., 1996; Schumann et al., 2004; Ostby et al., 2009). To our knowledge, there are no data on the development of the human amygdala between birth and 2 years of age, which would enable a better comparison of our results with those obtained during the corresponding developmental period in humans.

\section{Nuclei volumes and cell numbers}

Our findings of differential postnatal development of distinct amygdala nuclei in monkeys are consistent with previously published data in rats and rabbits, despite the fact that, at birth, primates are comparatively more mature than both rats and rabbits. Similar to the early and rapid maturation of the lateral, basal, and accessory basal amygdala nuclei that we observed in monkeys between birth and 3 months of age, the rat lateral and basal amygdala nuclei increase rapidly in size from birth to 3 weeks of postnatal age (P21), where their combined volume reaches about $90 \%$ of the volume observed at 6 months of age $(10 \%$ at P0, $40 \%$ at P7, and $80 \%$ at P14; Berdel et al., 1997b). This period of rapid enlargement is followed by a much slower maturation that extends beyond 3 months of age, when the basolateral amygdala has reached about $95 \%$ of the volume observed in 6month-old rats (Berdel et al., 1997b; Rubinow and Juraska, 2009). In the rabbit, the combined volume of the lateral, basal and accessory basal nuclei increases linearly from birth (12\% of adult value) to 4 months of age, when it reaches the value observed in 6-month-old animals (Jagalska-Majewska et al., 2003). Interestingly, and similar to what we found in monkeys, the medial nucleus reaches an adult volume between P5 and P11 in rats (Mizukami et al., 1983), an age at which the combined volume of the lateral and basal nuclei is still less than $80 \%$ of the adult value (Berdel et al., 1997b). Although the actual percentages of adult values differ between species, these data indicate that the medial nucleus matures relatively earlier than the lateral and basal nuclei in all species examined.

Considering that primates are born significantly more mature than rats and rabbits, the lack of postnatal changes in neuron numbers and neuronal soma volumes in monkeys are consistent with data in rats indicating a stable number of neurons after P7 and an adult-like neuronal soma size at P14 (Berdel et al., 1997a; Rubinow and Juraska, 2009). Nevertheless, a systematic stereological study of the postnatal development of the rat amygdala will be necessary to make direct comparisons and draw more meaningful parallels regarding the similarities or differences in the cellular maturational processes among different species.

Previous studies reported that postnatal neurogenesis occurs in the amygdala of mice (Shapiro et al., 2009), voles (Fowler et al., 2002), and monkeys (Bernier et al., 2002). In contrast, others have shown that although an enriched environment increases the proliferation of cells in the mouse amygdala, almost all of the cells express the oligodendrocyte progenitor marker Olig2 (Okuda et al., 2009). Our systematic quantitative analysis, using design-based stereological techniques, failed to detect any changes in mature neuron numbers in five of the main monkey amygdala nuclei from birth to adulthood. Interestingly, postnatal neurogenesis is much more prominent and unambiguously demonstrated in the dentate gyrus, but even in this brain region neurogenesis does not lead to changes in the total number of neurons in adult monkeys (that is, after a defined, postnatal developmental period; Jabès et al., 2010). In contrast, we found an increase in mature neuron number in the paralaminar nucleus from 1 year to 5-9 years of age, which appears to be due to the postnatal maturation of immature neurons already present at birth. The presence of immature neurons in the paralaminar nucleus is consistent with the presence of Bcl-2-positive cells reported previously (Bernier et al., 2002).

In sum, our quantitative estimates indicate that whether or not marginal postnatal neurogenesis exists in the monkey amygdala, it does not lead to detectable postnatal changes in total neuron numbers.

\section{Differential maturation of distinct amygdala circuits}

Our stereological data identified different patterns and stages of postnatal development that might reflect the maturation of distinct cellular processes and amygdala circuits (Fig. 9). The first stage was characterized by the dramatic enlargement of the deep nuclei of the amygdala (lateral, basal, and accessory basal nuclei) between birth and 3 months of age. The second stage was characterized 


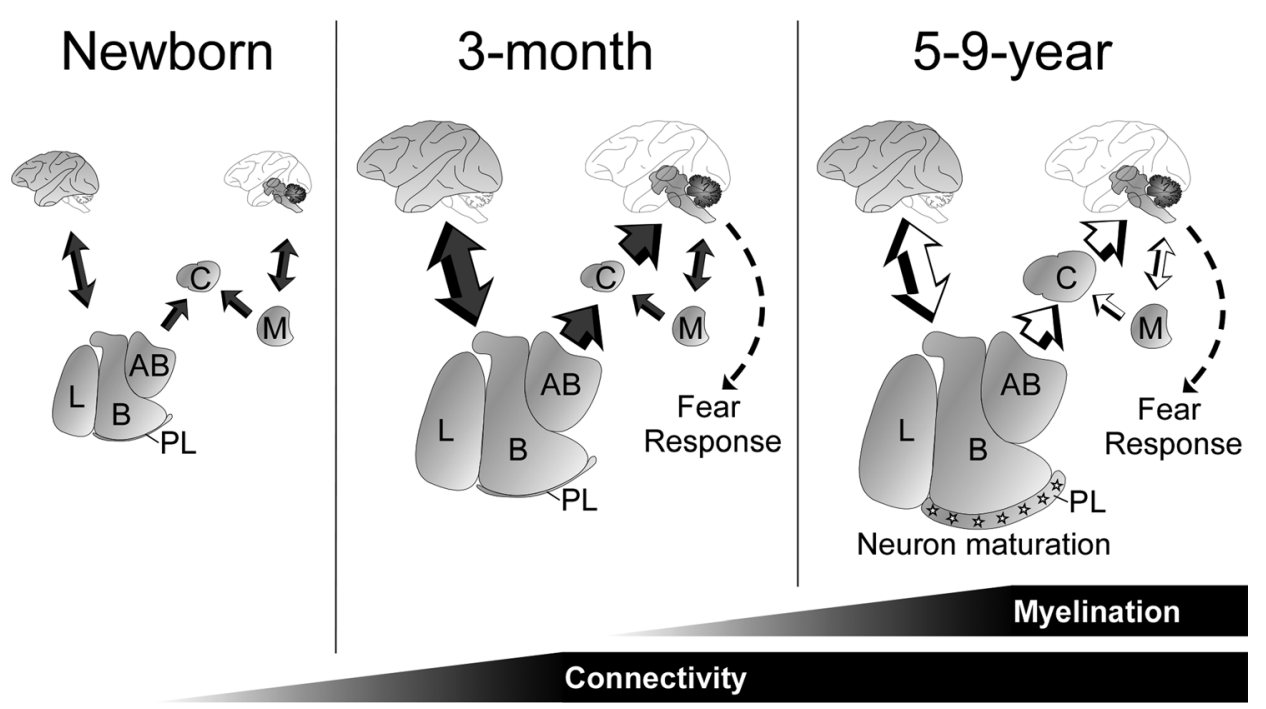

Figure 9. Schematic representation of the postnatal development of the monkey amygdala circuits. L: lateral; B: basal; $A B$ : accessory basal; C: central; M: medial; PL: paralaminar. Black arrow: unmyelinated axons; black and white arrow: myelinated axons.

by a continuous increase in size of all amygdala nuclei beyond 1 year of age. In addition, the central and paralaminar nuclei exhibited a notably slow and prolonged maturation.

\section{First stage: neuropil expansion}

In the absence of detectable changes in neuronal soma size or cell numbers during the first 3 months of life, the dramatic enlargement of the lateral, basal, and accessory basal nuclei of the monkey amygdala likely reflects an increase in neuropil volume. Combined, these three nuclei exhibited a $35 \%$ increase in volume between birth and 3 months of age. Interestingly, these three nuclei represent about $56 \%$ of the volume of the entire amygdala in monkeys, and the volumetric changes observed for the whole amygdala exhibited the same developmental profile as that observed for these nuclei. Volume estimates based on MRI analyses in monkeys are therefore likely to be dominated by the developmental changes in these three nuclei, whereas more subtle changes in other amygdala nuclei are likely to be masked. This is probably even more the case in humans, where these three nuclei represent about $69 \%$ of the size of the entire amygdala (Chareyron et al., 2011). Importantly, we did not find any changes in the numbers of neurons, astrocytes, or oligodendrocytes, or in the size of neuronal somas in these three nuclei during the first 3 months of postnatal life. It is thus reasonable to assume that neuropil expansion underlies the observed volumetric changes. Indeed, the neuropil, which is defined as the portion of neural tissue composed mostly of small dendrites and spines and fine glial processes, unmyelinated axons, and axon terminals (Bourgeois and Rakic, 1993; Bourgeois et al., 1994), represents the largest fraction of these nuclei. In contrast, the average volume occupied by neuronal somas in these three nuclei decreases from $11.2 \%$ at birth to $9.2 \%$ at 3 months of age and eventually reaches $6.3 \%$ at $5-9$ years of age.

An increase of neuropil volume might, in turn, reflect an increase in the connectivity of these nuclei. The lateral, basal, and accessory basal nuclei are highly interconnected with the neocortex (Amaral et al., 1992) and their volumetric expansion during the first 3 months of life parallels the volumetric expansion of the rest of the brain (current study; Malkova et al., 2006; Payne et al., 2010; Scott et al., submitted). Interestingly, the massive volumetric expansion of prefrontal cortical areas in the monkey has been linked to neuropil expansion during the first 2 months of postnatal life (Bourgeois et al., 1994). In rats, major changes in the interconnections between the basolateral amygdala and the prefrontal cortex occur between P7 and P19 (Bouwmeester et al., 2002a,b). In cats, an increase in total dendritic length in the basolateral amygdala has been observed during the first postnatal month (Wakefield and Levine, 1985). These observations suggest that neuropil expansion related to changes in interconnectivity with neocortical areas might underlie the volumetric increases of the lateral, basal, and accessory basal nuclei during the first 3 months of life. In contrast to the deep nuclei, the central and medial nuclei do not exhibit any increase in volume between birth and 3 months of age. These two nuclei are connected mainly with the thalamus, hypothalamus, and brainstem (Amaral et al., 1992). In contrast to cortical 
connections, the interconnections between the amygdala and the thalamic regions and substantia innominata do not change between P7 and P19 in rats, suggesting that these connections are already established shortly after birth (Bouwmeester et al., 2002a,b). The lack of significant volumetric changes of the monkey central and medial nuclei during the first postnatal year might thus reflect the lack of structural (and potentially functional) refinement of the interconnections between these nuclei and the rest of the brain. However, what is puzzling is the fact that the central nucleus exhibits a very significant enlargement after 1 year of age.

\section{Second stage: myelination}

We observed a continuous increase in the size of all amygdala nuclei from birth to young adulthood that was associated with an increase in the number of oligodendrocytes. This suggests that myelination of the amygdala circuits may underlie, at least in part, the late and continuous enlargement of amygdala nuclei after 3 months of age. Indeed, oligodendrocytes produce the myelin sheath that surrounds axons (Nave, 2010), and an increase in oligodendrocyte number has been linked to an increase in axon myelination during development (O'Kusky and Colonnier, 1982). The contribution of oligodendrocyte processes to the volumetric changes observed after 3 months of age was, however, not uniform across distinct amygdala nuclei. In the lateral, basal, and accessory basal nuclei, statistical analyses indicated that oligodendrocyte numbers were only partially related to the volumetric changes. Thus, other factors might also contribute to these changes. In the medial nucleus, the correlation was also low due to 1) high biological variability in this nucleus, and 2) a possible decrease in neuropil volume that has been suggested to occur during puberty (Zehr et al., 2006). In contrast, the correlation between volume and oligodendrocyte number was very high in the central nucleus, suggesting that myelination of fibers in this nucleus might contribute most to its volumetric maturation. In sum, despite subtle differences between individual amygdala nuclei, increases in oligodendrocyte number might underlie the continuous increase in overall amygdala volume until young adulthood.

\section{Paralaminar nucleus}

We quantified a population of immature cells in the paralaminar nucleus of the postnatal monkey amygdala, which developed into mature neurons after 1 year of age. Previous studies have noted the existence of immature cells expressing different markers of immature neurons in the paralaminar nucleus of: 1) monkeys: doublecortin (Zhang et al., 2009; Decampo and Fudge, 2011; Marlatt et al., 2011), PSA-NCAM (Bernier et al., 2002; Decampo and Fudge, 2011; Marlatt et al., 2011), Bcl2 protein (Bernier and Parent, 1998a,b; Bernier et al., 2002; Fudge, 2004), class III $\beta$-tubulin and TUC-4 (Bernier et al., 2002); 2) humans: Bcl-2 protein (Yachnis et al., 2000); and 3) rabbits: class III $\beta$-tubulin and PSA-NCAM (Luzzati et al., 2003, 2009), doublecortin and Tbr-1 (Luzzati et al., 2009). In particular, Yachnis et al. (2000) identified a population of immature cells in the ventrolateral region of the human amygdala, which are abundant throughout infancy, persist into adulthood, and are gradually reduced during adult life. Zhang et al. (2009) also reported that, although the number of doublecortin-expressing cells in the paralaminar nucleus decreases in adulthood, they remained present in 12-, 21-, and even 31-year-old monkeys, suggesting continued neuronal maturation throughout the lifespan. Thus, although several studies have previously provided evidence of the presence of immature cells in the paralaminar nucleus, our study is the first to quantify this population of immature cells and their development during early postnatal life. The postnatal maturation of this population of neurons should not be confounded with the temporal stream reported by Bernier et al. (2002). Although we cannot exclude the possibility that some immature neurons migrate, the fact that we found that their number does not change during postnatal development suggests that these cells were quiescent in the paralaminar nucleus and only matured after 1 year of age.

What needs to be investigated now is whether these late-maturing neurons in the paralaminar nucleus integrate into existing amygdala circuits and, if so, what their function might be. The delayed maturation of these neurons must constitute a prominent phenomenon, as these neurons represented $8 \%$ of the total number of mature neurons present in the basolateral portion of the amygdala (i.e., including the lateral, basal, accessory basal, and paralaminar nuclei) in young adult individuals. Unfortunately, only scant information is available about the connectivity of the paralaminar nucleus and there is no clear hypothesis about its function (Amaral et al., 1992; Decampo and Fudge, 2011). Some authors assume that the integration of new (i.e., recently mature) neurons in the amygdaloid complex may parallel the continuing addition of neurons in the olfactory bulb, as the amygdala receives direct olfactory inputs (Bernier et al., 2002; Arisi et al., 2011). This hypothesis is problematic, however, as the paralaminar nucleus, defined by the presence of immature cells, is undetectable in the rat (Chareyron et al., 2011). The amygdala is also interconnected with the hippocampus (Amaral et al., 1992; Decampo and Fudge, 2011) and as observed in the dentate gyrus (Jabès et al., 2010), the formation of new emotional memories could be facilitated by the integration of new neurons in 
the amygdala. Although a clear hypothesis about the function of the paralaminar nucleus is still lacking, the addition of recently mature neurons to existing circuits in adolescent and adult animals might contribute to increased plasticity and coding capacity in the amygdala (Decampo and Fudge, 2011).

\section{CONCLUSION}

We identified two stages of postnatal development of the primate amygdala. The first is characterized by a large increase in the volumes of the lateral, basal, and accessory basal nuclei between birth and 3 months of age, without any detectable changes in neuronal soma size or cell numbers, thus suggesting an increase in neuropil volume. The second stage is characterized by a slow and continuous increase in size of most amygdala nuclei from birth to young adulthood, which is accompanied by an increase in oligodendrocyte number. This stage likely reflects the postnatal myelination of amygdala circuits. We also quantified the maturation of a population of immature cells present in the paralaminar nucleus at birth, which further develop into mature neurons after 1 year of age. Our quantitative findings in monkeys have defined the normal time course of postnatal development of the primate amygdala at the cellular level. These data, which are likely a reasonable proxy for the development of the human amygdala, may provide the substrate for the formulation of models relating the perturbation of specific maturational processes to the etiologies of human psychiatric and neurological disorders.

\section{ACKNOWLEDGMENTS}

We thank the CNPRC staff, Jeff Bennett, Grégoire Favre, Jane Favre, Adeline Jabès, Danièle Uldry, and K.C. Wells for technical assistance at various stages of the project.

\section{LITERATURE CITED}

Aliashkevich AF, Yilmazer-Hanke D, Van Roost D, Mundhenk B, Schramm J, Blumcke I. 2003. Cellular pathology of amygdala neurons in human temporal lobe epilepsy. Acta Neuropathol 106:99-106.

Amaral DG, Price JL, Pitkänen A, Carmichael ST. 1992. Anatomical organization of the primate amygdaloid complex. In: Aggleton J, editor. The amygdala: neurobiological aspects of emotion, memory, and mental dysfunction. New York: Wiley-Liss. p1-66.

Arisi GM, Foresti ML, Mukherjee S, Shapiro LA. 2011. The role of olfactory stimulus in adult mammalian neurogenesis. Behav Brain Res [Epub ahead of print].

Aroniadou-Anderjaska V, Fritsch B, Qashu F, Braga MF. 2008. Pathology and pathophysiology of the amygdala in epileptogenesis and epilepsy. Epilepsy Res 78:102-116.

Baron-Cohen S, Ring HA, Bullmore ET, Wheelwright S, Ashwin C, Williams SC. 2000. The amygdala theory of autism. Neurosci Biobehav Rev 24:355-364.
Berdel B, Morys J, Maciejewska B. 1997a. Neuronal changes in the basolateral complex during development of the amygdala of the rat. Int J Dev Neurosci 15:755-765.

Berdel B, Morys J, Maciejewska B, Dziewiatkowski J. 1997b. Volume and topographical changes of the basolateral complex during the development of the rat's amygdaloid body. Folia Morphol (Warsz) 56:1-11.

Bernier PJ, Parent A. 1998a. The anti-apoptosis bcl-2 protooncogene is preferentially expressed in limbic structures of the primate brain. Neuroscience 82:635-640.

Bernier PJ, Parent A. 1998b. Bcl-2 protein as a marker of neuronal immaturity in postnatal primate brain. J Neurosci 18: 2486-2497.

Bernier PJ, Bedard A, Vinet J, Levesque M, Parent A. 2002. Newly generated neurons in the amygdala and adjoining cortex of adult primates. Proc Natl Acad Sci U S A 99: 11464-11469.

Berretta S, Pantazopoulos H, Lange N. 2007. Neuron numbers and volume of the amygdala in subjects diagnosed with bipolar disorder or schizophrenia. Biol Psychiatry 62: 884-893.

Bourgeois JP, Rakic P. 1993. Changes of synaptic density in the primary visual cortex of the macaque monkey from fetal to adult stage. J Neurosci 13:2801-2820.

Bourgeois JP, Goldman-Rakic PS, Rakic P. 1994. Synaptogenesis in the prefrontal cortex of rhesus monkeys. Cereb Cortex 4:78-96.

Bouwmeester H, Smits K, Van Ree JM. 2002a. Neonatal development of projections to the basolateral amygdala from prefrontal and thalamic structures in rat. J Comp Neurol 450:241-255.

Bouwmeester H, Wolterink G, van Ree JM. 2002b. Neonatal development of projections from the basolateral amygdala to prefrontal, striatal, and thalamic structures in the rat. J Comp Neurol 442:239-249.

Carlo CN, Stevens CF. 2011. Analysis of differential shrinkage in frozen brain sections and its implications for the use of guard zones in stereology. J Comp Neurol 519:2803-2810.

Cavedo E, Boccardi M, Ganzola R, Canu E, Beltramello A, Caltagirone C, Thompson PM, Frisoni GB. 2011. Local amygdala structural differences with $3 \mathrm{~T} \mathrm{MRI}$ in patients with Alzheimer disease. Neurology 76:727-733.

Chareyron LJ, Banta Lavenex P, Amaral DG, Lavenex P. 2011. Stereological analysis of the rat and monkey amygdala. J Comp Neurol [Epub ahead of print].

Courchesne E, Chisum HJ, Townsend J, Cowles A, Covington J, Egaas B, Harwood M, Hinds S, Press GA. 2000. Normal brain development and aging: quantitative analysis at in vivo MR imaging in healthy volunteers. Radiology 216: $672-682$.

Decampo D, Fudge J. 2012. Where and what is the paralaminar nucleus? A review on a unique and frequently overlooked area of the primate amygdala. Neurosci Biobehav Rev 36:520-535.

Drevets WC. 2003. Neuroimaging abnormalities in the amygdala in mood disorders. Ann N Y Acad Sci 985:420-444.

Fitting S, Booze RM, Hasselrot U, Mactutus CF. 2008. Differential long-term neurotoxicity of HIV-1 proteins in the rat hippocampal formation: a design-based stereological study. Hippocampus 18:135-147.

Fowler CD, Liu Y, Ouimet C, Wang Z. 2002. The effects of social environment on adult neurogenesis in the female prairie vole. J Neurobiol 51:115-128.

Fudge JL. 2004. Bcl-2 immunoreactive neurons are differentially distributed in subregions of the amygdala and hippocampus of the adult macaque. Neuroscience 127: 539-556. 
Giedd JN, Vaituzis AC, Hamburger SD, Lange N, Rajapakse JC, Kaysen D, Vauss YC, Rapoport JL. 1996. Quantitative MRI of the temporal lobe, amygdala, and hippocampus in normal human development: ages 4-18 years. J Comp Neurol 366:223-230.

Giedd JN, Blumenthal J, Jeffries NO, Castellanos FX, Liu H, Zijdenbos A, Paus T, Evans AC, Rapoport JL. 1999. Brain development during childhood and adolescence: a longitudinal MRI study. Nat Neurosci 2:861-863.

Grady MS, Charleston JS, Maris D, Witgen BM, Lifshitz J. 2003. Neuronal and glial cell number in the hippocampus after experimental traumatic brain injury: analysis by stereological estimation. J Neurotrauma 20:929-941.

Gundersen HJ. 1986. Stereology of arbitrary particles. A review of unbiased number and size estimators and the presentation of some new ones, in memory of William R. Thompson. J Microsc 143(Pt 1):3-45.

Gundersen HJ. 1988. The nucleator. J Microsc 151(Pt 1):3-21.

Gundersen HJ, Jensen EB. 1987. The efficiency of systematic sampling in stereology and its prediction. J Microsc 147(Pt 3):229-263.

Hamidi M, Drevets WC, Price JL. 2004. Glial reduction in amygdala in major depressive disorder is due to oligodendrocytes. Biol Psychiatry 55:563-569.

Humphrey T. 1968. The development of the human amygdala during early embryonic life. J Comp Neurol 132:135-165.

Ichinohe N, Hayashi M, Wakabayashi K, Rockland KS. 2009. Distribution and progression of amyloid-beta deposits in the amygdala of the aged macaque monkey, and parallels with zinc distribution. Neuroscience 159:1374-1383.

Jabès A, Banta Lavenex P, Amaral DG, Lavenex P. 2010. Quantitative analysis of postnatal neurogenesis and neuron number in the macaque monkey dentate gyrus. Eur J Neurosci 31:273-285.

Jabès A, Banta Lavenex P, Amaral DG, Lavenex P. 2011. Postnatal development of the hippocampal formation: a stereological study in macaque monkeys. J Comp Neurol 519: 1051-1070.

Jagalska-Majewska H, Wojcik S, Dziewiatkowski J, Luczynska A, Kurlapska R, Morys J. 2003. Postnatal development of the basolateral complex of rabbit amygdala: a stereological and histochemical study. J Anat 203:513-521.

Kalin NH, Shelton SE, Davidson RJ. 2004. The role of the central nucleus of the amygdala in mediating fear and anxiety in the primate. J Neurosci 24:5506-5515.

Kalmar JH, Wang F, Chepenik LG, Womer FY, Jones MM, Pittman B, Shah MP, Martin A, Constable RT, Blumberg HP. 2009. Relation between amygdala structure and function in adolescents with bipolar disorder. J Am Acad Child Adolesc Psychiatry 48:636-642.

Kim MJ, Loucks RA, Palmer AL, Brown AC, Solomon KM, Marchante AN, Whalen PJ. 2011. The structural and functional connectivity of the amygdala: from normal emotion to pathological anxiety. Behav Brain Res 223:403-410.

Knickmeyer RC, Gouttard S, Kang C, Evans D, Wilber K, Smith JK, Hamer RM, Lin W, Gerig G, Gilmore JH. 2008. A structural MRI study of human brain development from birth to 2 years. J Neurosci 28:12176-12182.

Kordower JH, Piecinski P, Rakic P. 1992. Neurogenesis of the amygdaloid nuclear complex in the rhesus monkey. Brain Res Dev Brain Res 68:9-15.

Kreczmanski $P$, Heinsen $H$, Mantua V, Woltersdorf $F$, Masson T, Ulfig N, Schmidt-Kastner R, Korr H, Steinbusch HW, Hof PR, Schmitz C. 2007. Volume, neuron density and total neuron number in five subcortical regions in schizophrenia. Brain 130(Pt 3):678-692.

Lavenex P, Steele MA, Jacobs LF. 2000a. The seasonal pattern of cell proliferation and neuron number in the dentate gyrus of wild adult eastern grey squirrels. Eur J Neurosci 12:643-648.

Lavenex P, Steele MA, Jacobs LF. 2000b. Sex differences, but no seasonal variations in the hippocampus of food-caching squirrels: a stereological study. J Comp Neurol 425: 152- 166.

Lavenex P, Banta Lavenex P, Bennet JL, Amaral DG. 2009. Postmortem changes in the neuroanatomical characteristics of the primate brain: hippocampal formation. J Comp Neurol 512:27-51.

Lawrie SM, Whalley HC, Job DE, Johnstone EC. 2003. Structural and functional abnormalities of the amygdala in schizophrenia. Ann N Y Acad Sci 985:445-460.

Luzzati F, Peretto P, Aimar P, Ponti G, Fasolo A, Bonfanti L. 2003. Glia-independent chains of neuroblasts through the subcortical parenchyma of the adult rabbit brain. Proc Natl Acad Sci U S A 100:13036-13041.

Luzzati F, Bonfanti L, Fasolo A, Peretto P. 2009. DCX and PSA-NCAM expression identifies a population of neurons preferentially distributed in associative areas of different pallial derivatives and vertebrate species. Cereb Cortex 19: 1028-1041.

Malkova L, Heuer E, Saunders RC. 2006. Longitudinal magnetic resonance imaging study of rhesus monkey brain development. Eur J Neurosci 24:3204-3212.

Marlatt MW, Philippens I, Manders E, Czeh B, Joels M, Krugers $\mathrm{H}$, Lucassen PJ. 2011. Distinct structural plasticity in the hippocampus and amygdala of the middle-aged common marmoset (Callithrix jacchus). Exp Neurol 230:291-301.

Mizukami S, Nishizuka M, Arai Y. 1983. Sexual difference in nuclear volume and its ontogeny in the rat amygdala. Exp Neurol 79:569-575.

Morris JA, Jordan CL, Breedlove SM. 2008. Sexual dimorphism in neuronal number of the posterodorsal medial amygdala is independent of circulating androgens and regional volume in adult rats. J Comp Neurol 506:851-859.

Mosconi MW, Cody-Hazlett H, Poe MD, Gerig G, Gimpel-Smith R, Piven J. 2009. Longitudinal study of amygdala volume and joint attention in 2- to 4-year-old children with autism. Arch Gen Psychiatry 66:509-516.

Nave KA. 2010. Myelination and support of axonal integrity by glia. Nature 468:244-252.

O’Kusky J, Colonnier M. 1982. Postnatal changes in the number of astrocytes, oligodendrocytes, and microglia in the visual cortex (area 17) of the macaque monkey: a stereological analysis in normal and monocularly deprived animals. J Comp Neurol 210:307-315.

Okuda H, Tatsumi K, Makinodan M, Yamauchi T, Kishimoto T, Wanaka A. 2009. Environmental enrichment stimulates progenitor cell proliferation in the amygdala. J Neurosci Res 87:3546-3553.

Ostby Y, Tamnes CK, Fjell AM, Westlye LT, Due-Tonnessen P, Walhovd KB. 2009. Heterogeneity in subcortical brain development: a structural magnetic resonance imaging study of brain maturation from 8 to 30 years. J Neurosci 29: $11772-11782$.

Palackal T, Neuringer M, Sturman J. 1993. Laminar analysis of the number of neurons, astrocytes, oligodendrocytes and microglia in the visual cortex (area 17) of 6- and 12month-old rhesus monkeys fed a human infant soy-protein formula with or without taurine supplementation from birth. Dev Neurosci 15:54-67.

Payne C, Machado CJ, Bliwise NG, Bachevalier J. 2010. Maturation of the hippocampal formation and amygdala in Macaca mulatta: a volumetric magnetic resonance imaging study. Hippocampus 20:922-935.

Pfefferbaum A, Mathalon DH, Sullivan EV, Rawles JM, Zipursky RB, Lim KO. 1994. A quantitative magnetic resonance 
imaging study of changes in brain morphology from infancy to late adulthood. Arch Neurol 51:874-887.

Pitkänen A, Amaral DG. 1998. Organization of the intrinsic connections of the monkey amygdaloid complex: projections originating in the lateral nucleus. J Comp Neurol 398: 431-458.

Price JL, Russchen FT, Amaral DG. 1987. The limbic region. II: The amygdaloid complex. In: Björklund A, Hökfelt T, Swanson LW, editors. Handbook of chemical neuroanatomy. Vol. 5. Integrated systems of the CNS. Part I. Amsterdam: Elsevier. p279-388.

Rubinow MJ, Juraska JM. 2009. Neuron and glia numbers in the basolateral nucleus of the amygdala from preweaning through old age in male and female rats: a stereological study. J Comp Neurol 512:717-725.

Schumann CM, Amaral DG. 2006. Stereological analysis of amygdala neuron number in autism. J Neurosci 26: 7674-7679.

Schumann CM, Hamstra J, Goodlin-Jones BL, Lotspeich LJ, Kwon $\mathrm{H}$, Buonocore $\mathrm{MH}$, Lammers CR, Reiss AL, Amaral DG. 2004. The amygdala is enlarged in children but not adolescents with autism; the hippocampus is enlarged at all ages. J Neurosci 24:6392-6401.

Schumann CM, Barnes CC, Lord C, Courchesne E. 2009. Amygdala enlargement in toddlers with autism related to severity of social and communication impairments. Biol Psychiatry 66:942-949.

Shapiro LA, Ng K, Zhou QY, Ribak CE. 2009. Subventricular zone-derived, newly generated neurons populate several olfactory and limbic forebrain regions. Epilepsy Behav 14 Suppl 1:74-80.

Tottenham N, Sheridan MA. 2009. A review of adversity, the amygdala and the hippocampus: a consideration of developmental timing. Front Hum Neurosci 3:68.

Tye KM, Prakash R, Kim SY, Fenno LE, Grosenick L, Zarabi H, Thompson KR, Gradinaru V, Ramakrishnan C, Deisseroth K. 2011. Amygdala circuitry mediating reversible and bidirectional control of anxiety. Nature 471:358-362.
Ulfig N, Setzer M, Bohl J. 2003. Ontogeny of the human amygdala. Ann N Y Acad Sci 985:22-33.

Usher J, Leucht S, Falkai P, Scherk H. 2010. Correlation between amygdala volume and age in bipolar disorder - a systematic review and meta-analysis of structural MRI studies. Psychiatry Res 182:1-8.

Vereecken TH, Vogels OJ, Nieuwenhuys R. 1994. Neuron loss and shrinkage in the amygdala in Alzheimer's disease. Neurobiol Aging 15:45-54.

Wakefield CL, Levine MS. 1985. Early postnatal development of basolateral amygdala in kitten: a Golgi morphometric analysis. Brain Res Bull 14:159-167.

West MJ, Gundersen HJ. 1990. Unbiased stereological estimation of the number of neurons in the human hippocampus. J Comp Neurol 296:1-22.

West MJ, Slomianka L, Gundersen HJ. 1991. Unbiased stereological estimation of the total number of neurons in thesubdivisions of the rat hippocampus using the optical fractionator. Anat Rec 231:482-497.

Yachnis AT, Roper SN, Love A, Fancey JT, Muir D. 2000. Bcl-2 immunoreactive cells with immature neuronal phenotype exist in the nonepileptic adult human brain. J Neuropathol Exp Neurol 59:113-119.

Yang TT, Simmons AN, Matthews SC, Tapert SF, Frank GK, Max JE, Bischoff-Grethe A, Lansing AE, Brown G, Strigo IA, Wu J, Paulus MP. 2010. Adolescents with major depression demonstrate increased amygdala activation. J Am Acad Child Adolesc Psychiatry 49:42-51.

Zehr JL, Todd BJ, Schulz KM, McCarthy MM, Sisk CL. 2006. Dendritic pruning of the medial amygdala during pubertal development of the male Syrian hamster. J Neurobiol 66: 578-590.

Zhang XM, Cai Y, Chu Y, Chen EY, Feng JC, Luo XG, Xiong K, Struble RG, Clough RW, Patrylo PR, Kordower JH, Yan XX. 2009. Doublecortin-expressing cells persist in the associative cerebral cortex and amygdala in aged nonhuman primates. Front Neuroanat 3:17. 